\title{
TSC2-extracellular matrix crosstalk controls pulmonary vascular proliferation and pul- monary hypertension
}

Authors: Yuanjun Shen ${ }^{1}$, Dmitry A. Goncharov ${ }^{1}$, Andressa Pena ${ }^{2}$, Jeffery Baust ${ }^{2}$, Andres Chavez Barragan ${ }^{2}$, Arnab Ray ${ }^{2}$, Analise Rode ${ }^{2}$, Timothy N. Bachman ${ }^{2}$, Baojun Chang ${ }^{2}$, Mauricio Rojas $^{4}$, Horace DeLisser ${ }^{3}$, Ana L. Mora ${ }^{4}$, Tatiana V. Kudryashova ${ }^{1}$, and Elena. A. Goncharova ${ }^{*}$

\author{
Affiliations: \\ ${ }^{1}$ Lung Center, Division of Pulmonary, Critical Care and Sleep Medicine, University of Califor- \\ nia, Davis School of Medicine, Davis, CA, USA \\ ${ }^{2}$ Pittsburgh Heart, Lung, Blood and Vascular Medicine Institute, University of Pittsburgh School \\ of Medicine, Pittsburgh, PA, USA \\ ${ }^{3}$ Department of Pathology and Laboratory Medicine, Pulmonary Vascular Disease Program, \\ University of Pennsylvania Perelman School of Medicine, Philadelphia, PA, USA \\ ${ }^{4}$ Division of Pulmonary, Critical Care and Sleep Medicine, The Ohio State University College og \\ Medicine, Columbus, OH, USA \\ *To whom correspondence should be addressed: Elena Goncharova, email: eagoncha- \\ rova@ucdavis.edu
}

One Sentence Summary: TSC2 acts as mechanosensor and mechanotransducer, integrating ECM composition and stiffness with pro-proliferative signaling in pulmonary vasculature; its deficiency in PA vascular smooth muscle cells results in ECM remodeling, hyper-proliferation and pulmonary hypertension, which could be reversed by pharmacological restoration of functional TSC2.

Abstract: Increased proliferation and survival of resident cells in small pulmonary arteries (PA) are important drivers of pulmonary hypertension (PH). Tuberous sclerosis complex 2 (TSC2) is a negative regulator of mTOR complex 1 and cell growth. Here we show that TSC2 is deficient in small remodeled PA/PA vascular smooth muscle cells (PAVSMC) from human PAH and experimental PH lungs. TSC2 deficiency was reproduced in vitro by maintaining PAVSMC on pathologically stiff substrates and was required for stiffness-induced proliferation, accumulation of transcriptional co-activators YAP/TAZ and up-regulation of mTOR. Depletion of TSC2 reproduced $\mathrm{PH}$ features in vitro in human PAVSMC and in vivo in SM22-Tsc2+/- mice. TSC2 loss in PAVSMC was supported by YAP and led to the up-regulation of YAP/TAZ and mTOR via modulating the extracellular matrix (ECM) composition. ECM, produced by TSC2-deficient PAVSMC, promoted growth of non-diseased PA adventitial fibroblasts and PAVSMC, which, in turn, was prevented by $\alpha 5 \beta 1$ integrin receptor antagonist ATN161. In vitro, molecular and pharmacological (SRT2104) restoration of TSC2 down-regulated YAP/TAZ, mTOR, and ECM production, inhibited proliferation and induced apoptosis in human PAH PAVSMC. In vivo, orally administrated SRT2104 restored TSC2, resolved pulmonary vascular remodeling, PH, and improved right heart in two rodent models of PH. Thus, PAVSMC TSC2 is a critical integrator of ECM composition and stiffness with pro-proliferative signaling and $\mathrm{PH}$, and the restoration of functional TSC2 could be an attractive therapeutic option to treat $\mathrm{PH}$. 


\section{Non-standard Abbreviations and Acronyms}

\begin{tabular}{|c|c|}
\hline BrdU & Bromodeoxyuridine \\
\hline BSA & Bovine serum albumin \\
\hline CollA1 & Collagen 1A1 \\
\hline DAPI & 4',6-diamidino-2-phenylindole \\
\hline $\mathrm{ECM}$ & Extracellular matrix \\
\hline ET-1 & Endotelin-1 \\
\hline $\mathrm{FN}$ & Fibronectin \\
\hline GFP & Green fluorescent protein \\
\hline $\mathrm{H} \& \mathrm{E}$ & Hematoxylin and eosin \\
\hline IGF-1 & Insulin growth factor 1 \\
\hline IL-6 & Interleukin-6 \\
\hline IPAH & Idiopathic pulmonary arterial hypertension \\
\hline LAM & Lymphangioleiomyomatosis \\
\hline LV & Left ventricular/ventricle \\
\hline MAP & Mean arterial pressure \\
\hline mTOR & Mechanistic target of rapamycin \\
\hline mTORC & Mechanistic target of rapamycin complex \\
\hline PA & Pulmonary artery \\
\hline PA MT & Pulmonary artery medial thickness \\
\hline PAAF & Pulmonary artery adventitial fibroblast \\
\hline PAEC & Pulmonary artery endothelial cell \\
\hline PAH & Pulmonary arterial hypertension \\
\hline PAP & PA pressure \\
\hline PAVSMC & Pulmonary artery vascular smooth muscle cells \\
\hline PDGF-BB & Platelet-derived growth factor-BB \\
\hline $\mathrm{PH}$ & Pulmonary hypertension \\
\hline RV & Right ventricular/ventricle \\
\hline SIRT1 & Sirtuin 1 \\
\hline sLVP & Systolic left ventricular pressure \\
\hline SM22 & Smooth muscle protein 22-alpha \\
\hline SMA & Smooth muscle $\alpha$-actin \\
\hline sRVP & Systolic right ventricular pressure \\
\hline $\mathrm{SuHx}$ & SU5416/Hypoxia \\
\hline $\mathrm{TNF}-\alpha$ & Tumor necrosis factor- $\alpha$ \\
\hline TSC2 & Tuberous sclerosis complex 2 \\
\hline TUNEL & $\begin{array}{l}\text { Terminal deoxynucleotidyltransferase-mediated dUTP-biotin nick end label- } \\
\text { ing }\end{array}$ \\
\hline WT & Wild type \\
\hline YAP & Yes-associated protein \\
\hline
\end{tabular}




\section{Introduction}

Pulmonary arterial hypertension (PAH), a progressive and rapidly fatal disease with a high mortality rate and no curative options (1), represents a serious public health problem with continuously increasing death and hospitalization rates (2-4). PAH manifests by vasoconstriction and remodeling of small pulmonary arteries (PA) (5-10) leading to chronically increased PA pressure and right ventricular afterload and resulting in right heart failure and death (4). Available therapies fail to reverse established pulmonary vascular remodeling or prevent disease progression (5, 9), and development of novel anti-proliferative/anti-remodeling therapies is an area of unmet important need.

Increased proliferation and survival of resident pulmonary vascular cells, a key components of PA remodeling $(8,11,12)$, are induced by the combination of soluble and insoluble stimuli, such as excessive production of growth factors and pro-inflammatory mediators and stiffening and remodeling of the extracellular matrix (ECM). As PAH progresses, PA vascular smooth muscle cells (PAVSMC) undergo a switch to the secretory, proliferative, apoptosis-resistant phenotype, which is self-supported by constitutive inhibition of growth suppressor cassette HIPPO-LATS1 and consequent up-regulation of its pro-proliferative downstream effectors transcriptional coactivators Yes-associated protein (YAP)/TAZ and the mechanistic target of rapamycin (mTOR) complex 1 (mTORC1) and mTORC2 (7-9, 12-15). The mechanisms coordinating growthpromoting signals with proliferative responses of resident PA cells in PAH are not completely understood, and available anti-proliferative therapeutic strategies are challenging due to their side effects.

Growth suppressor tuberous sclerosis complex 2 (TSC2) (tuberin) is a negative regulator of mTORC1, cell growth and proliferation (16). Deficiency or mutational inactivation of TSC2 is linked to proliferative diseases such as cancer, tuberous sclerosis and pulmonary lymphangioleiomyomatosis (LAM) (16-18). Several lines of evidence suggest that TSC2 may act as a coordinator of mTORC1 and HIPPO-YAP/TAZ pathways in PAH pulmonary vasculature. First, mTORC1 is activated in small remodeled PAs and contributes to human PAH PAVSMC proliferation, VSM remodeling and experimental PH in mice $(7,19,20)$. Second, mTOR-induced accumulation of YAP has been reported in Tsc2-null cells (21). Next, mice with VSM-specific knock-down of Tsc1 (a binding partner of TSC2 protecting it from the degradation) develop PH (22). Lastly, a subset of patients with pulmonary LAM (caused by TSC somatic mutations or loss of heterozygosity) develop "out-of-proportion" pre-capillary $\mathrm{PH}$, which can't be fully explained by hypoxemia and is likely attributed to the loss of pulmonary vascular TSC function (23).

In the present study, we aimed to determine the role of TSC2 in pulmonary vascular hyperproliferation in PAH. We found that TSC2 acts as a mechanosensor and mechanotransducer, and its deficiency in smooth muscle cells from small PAs permits up-regulation of YAP-TAZ and mTOR, increases PAVSMC proliferation, survival, and remodeling, and promotes $\mathrm{PH}$. We also provide a novel mechanistic link from PAVSMC-specific TSC2 deficiency to excessive ECM production, ECM-dependent activation of YAP/TAZ and mTOR, and increased growth of PAVSMC and PA adventitial fibroblasts (PAAF). Lastly, we demonstrate benefits of TSC2 restoration by SRT2104 to inhibit YAP/TAZ and mTOR axes, reverse pulmonary vascular remodeling, and reduce $\mathrm{PH}$. 


\section{Results}

\section{TCS2 is deficient in PAVSMC from human PAH lungs}

To determine the status of TSC2 in human PAH lungs, we first performed immunohistochemical and immunoblot analysis of lung tissue specimens from subjects with PAH and non-diseased (control) donor lungs (see Table S1 for human subjects' characteristics). We found that TSC2 protein levels are markedly lower in smooth muscle $\alpha$-actin (SMA)-positive areas and whole tissue lysates of small PAs from PAH lungs compared to controls (Fig. 1a-d). Supporting our observations, PAVSMC from small $(<1.5 \mathrm{~mm}$ outer diameter) human PAH PAs had significantly reduced TSC2 protein content (Fig. 1e, f) and significantly higher non-stimulated growth and proliferation than cells from non-diseased (control) subjects (Fig. 1g, h). We did not observe TSC2 deficiency in human PAH PA endothelial cells (PAEC) and PAAF (Fig. S1). Together, these data demonstrate that TSC2 is deficient in PAVSMC in small remodeled PAs in human PAH lungs.

\section{TSC2 deficiency enables PAVSMC hyper-proliferation, remodeling, and PH}

To determine the functional significance of TSC2 deficiency, we first performed siRNA-induced TSC2 depletion in human control PAVSMC. Transfection with siTSC2 significantly increased DNA synthesis (BrdU incorporation) and cell growth compared to the cells transfected with control siRNA (Fig. 1i-k). To test in vivo consequences of TSC2 deficiency, we next developed mice with SMC-specific Tsc2 knockout by crossing Tsc2 ${ }^{\text {flox/flox }}$ mice and Tagln (Sm22)-cre mice (13). Homozygous knockout of Tsc2 was embryonically lethal. Mice with heterozygous deletion of Tsc2 (Tsc2 ${ }^{+/}$) (Fig. S2) developed spontaneous mild PH as early as at nine weeks of age. Compared to the same-age wild type controls (WT), male SM22-Tsc2 ${ }^{+/-}$mice had significantly higher medial thickness of small $(<150 \mu \mathrm{m})$ PAs (PA MT) (Fig. 11, m), elevated systolic right ventricular (RV) pressure (sRVP) (Fig. 1n), and RV hypertrophy (Fulton index) (Fig. 1o). Four out of six female mice also developed mild PH (sRVP $\geq 30 \mathrm{mmHg}$ ). Together, these data demonstrate that TSC2 deficiency results in increased PAVSMC proliferation, VSM remodeling, and spontaneous $\mathrm{PH}$.

\section{TSC2 loss is induced by substrate stiffening, enables YAP/TAZ accumulation and PAVSMC growth}

Hyper-proliferation of PAVSMC in PAH is induced by multiple soluble (growth factors, inflammatory mediators) and insoluble factors (ECM composition and stiffness) (9, 11). To identify pro-PAH stimuli that induce TSC2 deficiency in PAVSMC, we exposed control human PAVSMC to the soluble growth factors and pro-inflammatory mediators (platelet-derived growth factor-BB (PDGF-BB), insulin growth factor 1 (IGF-1), interleukin-6 (IL-6), tumor necrosis factor- $\alpha$ (TNF- $\alpha$ ) and endotelin-1 (ET-1), or maintained the cells on the matrices of a different composition (collagen 1, collagen IV, fibronectin, laminin) or stiffness (physiological $0.2 \mathrm{kPa}$ and pathological $25 \mathrm{kPa})(8,11,13)$. We found that TSC2 protein levels were moderately decreased in PAVSMC stimulated by PDGF-BB or maintained on the plates covered with collagen I (Fig. 2a-d). Importantly, maintenance of PAVSMC on the pathologically stiff $(25 \mathrm{kPa})(8,12,14,15)$ matrices dramatically reduced TSC2 protein content and significantly increased cell growth compared to the cells seated on physiologically soft $(0.2 \mathrm{kPa})$ substrates (Fig. 2e-g). To determine whether TSC2 modulates stiffness-induced PAVSMC growth, we transfected control hu- 
man PAVSMC seeded on the stiff $(25 \mathrm{kPa})$ matrices with mammalian vectors expressing GFPTSC2 or control GFP. GFP-TSC2-transfected PAVSMC had 2 times lower growth on stiff matrices than GFP-transfected cells (Fig. 2h), suggesting that TSC2 acts as a mechanosensor and mechanotransducer, and TSC2 deficiency in PAVSMC is induced by increased matrix stiffness and is required for stiffness-induced cell growth.

Stiffening of small PAs drives pulmonary vascular cell proliferation and remodeling in PAH via transcriptional co-activators YAP/TAZ, which act, at least in part, via up-regulating proproliferative/pro-survival Akt-mTOR signaling $(8,12,14)$. Interestingly, re-expression of TSC2 in control PAVSMC maintained on the stiff matrices not only significantly decreased phosphorylation of ribosomal protein $\mathrm{S} 6$, a molecular signature of mTORC1 activation (Fig. $2 \mathbf{i}$, j), but also significantly reduced YAP/TAZ protein levels compared to the GFP-expressing cells (Fig. 2i, j). Supporting our findings, siRNA-dependent depletion of TSC2 in control human PAVSMC resulted in a significant increase of mTORC1-specific S6 phosphorylation, accumulation of YAP/TAZ and elevated phospho-S473-Akt compared to cells transfected with control siRNA (Fig. 2k, l). These data show that TSC2 deficiency in PAVSMC is required for stiffness-induced PAVSMC growth and up-regulation of YAP/TAZ and mTOR.

\section{TSC2 loss up-regulates YAP/TAZ, mTOR and PAVSMC proliferation via ECM remodeling}

The ECM remodeling is an important factor that facilitates hyper-proliferation of resident PA cells in PAH. Because YAP and TAZ facilitate resident pulmonary vascular cell proliferation in PAH via ECM remodeling $(8,11)$, we hypothesized that, in addition to canonical Rhebdependent activation of mTORC1, TSC2 deficiency in PAH PAVSMC may facilitate proproliferative signaling via modulating ECM production. In agreement with published studies (8, 11), PAVSMC from human PAH lungs had higher fibronectin and collagen 1A protein content compared to controls (Fig. 3a, b). Importantly, we found that transfection with siRNA TSC2 significantly increased fibronectin and collagen 1A protein levels in control human PAVSMC (Fig. 3c, d), suggesting that TSC2 loss facilitates production of the two key ECM proteins involved in PAH.

Next, we evaluated whether TSC2 loss modulates pro-proliferative signaling of neighboring cells via ECM. We prepared de-cellularized matrices from control human PAVSMC infected with lentiviruses producing shTSC2 or control shRNA and used these cell-free matrices as substrates for plating of control human PAVSMC (Fig. 3e). We found that control PAVSMC, seeded on the matrices produced by shTSC2-infected control PAVSMC, had significantly higher YAP/TAZ protein levels, increased S473-Akt and ribosomal protein S6 phosphorylation rates, and elevated growth and proliferation compared to the cells seeded on the matrices produced by shContr-infected PAVSMC (Fig. 3f-I), demonstrating that TSC2-deficient PAVSMC up-regulate YAP/TAZ, Akt, mTOR, and cell proliferation via ECM. To further confirm our observations, we maintained control PAVSMC on the cell-free matrices, produced by shTSC2-infected PAVSMC, in the presence of ATN-161, a small peptide antagonist of integrin $\alpha 5 \beta 1$, and BTT-3033, a selective inhibitor of integrin $\alpha_{2} \beta_{1}$, to block cell binding with fibronectin and collagen respectively (Fig. 3e) and performed a cell growth assay. Interestingly, ATN-161, but not BTT3033, prevented matrix-induced PAVSMC growth (Fig. 3m), suggesting that TSC2 loss promotes growth of PAVSMC via regulating extracellular fibronectin content. Supporting the relevance of these findings to human PAH, control PAVSMC seeded at the de-cellularized ECM, produced by human PAH PAVSMC, had higher S-473Akt and mTORC1-specific S6 phosphorylation rates and YAP/TAZ protein content than cells maintained on the matrices produced by non-diseased (con- 
trol) PAVSMC (Fig. S3). Collectively, these data demonstrate that TSC2 deficiency promotes YAP/TAZ and mTOR up-regulation and PAVSMC proliferation via ECM remodeling.

Interestingly, in contrast to stiffness-induced TSC2 deficiency (Fig. 2e, f), control PAVSMC seeded on the "diseased" matrices produced by TSC2-deficient control or PAH PAVSMC had up-regulated YAP/TAZ and mTOR without reduction of TSC2 protein levels (Fig. 3f-i, S3). These data support our observations that TSC2 acts upstream of YAP/TAZ and mTOR via regulating ECM and suggest an existence of ECM composition-independent mechanism(s) maintaining self-sustaining TSC2 deficiency in PAH PAVSMC. Because mTOR acts both upstream (mTORC2) and downstream (mTORC1) of TSC2 (17), and both mTORC2 and mTORC1 are upregulated and act downstream of YAP/TAZ in human PAH PAVSMC $(7,8)$, we hypothesized that stiffness-independent TSC2 deficiency could be self-supported via a YAP/mTORC2 feedforward loop. Supporting our hypothesis, depletion of YAP with specific siRNA led to TSC2 accumulation in human PAH PAVSMC compared to cells transfected with control siRNA (Fig. S4). However, treatment of human PAH PAVSMC with either mTOR kinase inhibitor PP242 (which inhibits mTOR in both mTORC1 and mTORC2) or allosteric mTORC1 inhibitor rapamycin did not increase TSC2 protein levels or reduce YAP/TAZ accumulation (Fig. S5), suggesting that TSC2 deficiency in PAH PAVSMC is supported by YAP in the mTOR-independent manner.

\section{ECM produced by TSC2-deficient PAVSMC induces growth of PAAF}

Because changes in ECM composition affect the proliferative response of neighboring pulmonary vascular cells, we next tested whether the matrix, produced by TSC2-deficient PAVSMC, modulates growth of other resident pulmonary vascular cells. We seeded control human PAEC and PAAF on the matrices produced by control human PAVSMC infected with adenovirus producing shTSC2 or control shRNA (shContr) (Fig. 3e). We found that control PAAF, but not PAEC, maintained on the matrices from shTSC2-infected control PAVSMC, had significantly higher cell growth compared to the cells seeded on the matrices produced by shContr-infected PAVSMC (Fig. 3n, o). These data show that TSC2 deficiency in PAVSMC results in dysregulated ECM production, which promotes growth of PAAF.

\section{Restoration of TSC2 suppresses proliferation, induces apoptosis in PAH PAVSMC}

To evaluate potential benefits of restoring functional TSC2 to target increased ECM proteins' production, proliferation and survival of PAVSMC from human PAH lungs, we transfected human PAH PAVSMC with mammalian vectors expressing GFP-TSC2 or control GFP. We found that TSC2 suppressed mTORC1-dependent S6 phosphorylation, and significantly reduced YAP/TAZ protein levels, Akt phosphorylation rates, and fibronectin and collagen 1A production compared to GFP-expressing cells (Fig. 4a,b, S6a). Importantly, expression of TSC2 suppressed PAH PAVSMC proliferation (Fig. 4c, Fig. S6b) and induced accumulation of Cleaved Caspase 3 and significant apoptosis (Fig. 4d, e), suggesting that restoration of TSC2 may be considered as an attractive therapeutic strategy to suppress both YAP/TAZ and mTOR pathways, halt excessive ECM production, inhibit proliferation, and induce apoptosis in PAH PAVSMC.

\section{SRT2104 reverses PAH PAVSMC phenotype via restoration of TSC2}

Next, we evaluated potential pharmacological strategies to restore functional TSC2 in human PAH PAVSMC. TSC2 is regulated by direct phosphorylation, which either prevents of promotes 
its degradation (17), and epigenetic modifications, such as deacetylation by SIRT1 (24). Known positive and negative regulators of TSC2 involved in PAH are Akt and AMPK. Akt is activated, while AMPK is inhibited in human PAH PAVSMC, and either inhibition of Akt or activation of AMPK suppresses mTORC1 and PAH PAVSMC proliferation (8, 19, 25-28). Intriguingly, we found that the inhibition of Akt or activation of AMPK, while successfully reducing mTORC1dependent S6 phosphorylation, did not increase TSC2 protein levels in human PAH PAVSMC (Fig. S7). Together with an inability of mTORC1/2 inhibitor PP242 to restore TSC2 in PAH PAVSMC (Fig. S5), our data suggest that mTORC2, Akt and AMPK act downstream of or in parallel to TSC2, and its targeting couldn't restore PAH-specific TSC2 deficiency.

Next, we tested the effect of SIRT1 activator SRT2104. We found that treatment of human PAH PAVSMC with SRT2104 significantly increased TSC2 protein levels and suppressed mTORC1dependent S6 phosphorylation (Fig. 5a, b, e), showing that SRT2104 restores functional TSC2. Importantly, SRT2104 reduced YAP/TAZ accumulation, decreased S473Akt phosphorylation rates, collagen 1A and fibronectin protein levels (Fig. 5a, c, d, f, g, h), inhibited proliferation, and promoted apoptosis in PAH PAVSMC (Fig. 5i-k). Importantly, SRT2104 also slowed down growth of control PAVSMC on the pathologically stiff matrices (Fig. 5l), suggesting potential benefits of SRT2104 in targeting both, self-sustaining and stiffness-induced PAVSMC proliferation in PAH.

To test whether SRT2104 acts via TSC2, we performed a "rescue" experiment by transfecting human PAH PAVSMC with siRNA TSC2 or control siRNA with and without SRT2104 treatment. We found that siRNA TSC2 prevented SRT2104-induced inhibition of the TSC2 downstream effector P-S6, reversed SRT2104-induced inhibition of cell growth and proliferation, and protected cells from SRT2104-induced apoptosis (Fig.5 m-q). In aggregate, the data show that SRT2104 acts via targeting TSC2 and that restoration of TSC2 by SRT2104 inhibits proliferation and induces apoptosis in human PAH PAVSMC.

\section{SRT2104 restores Tsc2 in small PAs, reduces established PH in mice and rats}

To evaluate the potential benefits of pharmacological restoration of TSC2 in vivo, we first examined whether short-term treatment of mice with SU5416/hypoxia (SuHx)-induced PH leads to Tsc2 accumulation in small PAs. SRT2104 and vehicle were administrated via gavage at days 15-21 after PH induction; negative controls were same-age same-gender mice maintained under normoxia (Fig. 6a). Like in human $\mathrm{PAH}$, the vehicle-treated mice from $\mathrm{SuHx}$ group (SuHx+Vehicle) had reduced Tsc2 protein levels in SMA-positive areas of small PAs (Fig. 6b), suggesting that similar mechanisms are shared. As expected, mice in the $\mathrm{SuHx}+$ Vehicle group developed pulmonary vascular remodeling and $\mathrm{PH}$ as evidenced by significantly higher PA medial thickness (PA MT), systolic right ventricular pressure (sRVP), PA pressure (PAP), and RV hypertrophy (Fig. 6b-f). The SRT2104-treated mice (SuHx-SRT2104 group) had higher Tsc2 protein content in small PAs and significantly lower PA MT, sRVP, PAP, and RV hypertrophy compared to vehicle-treated SuHx mice (Fig. 6b-f). We observed no significant differences between male and female mice. Systolic left ventricular pressure (sLVP), mean arterial pressure (MAP), and heart rate were not significantly different between $\mathrm{SuHx}+$ Vehicle and SuHx+SRT2014 groups (Fig. S8a-c). These data show that short-term SRT2104 treatment elevates Tsc2, attenuates VSM remodeling, $\mathrm{PH}$, and improves RV hypertrophy in mice with SuHxinduced $\mathrm{PH}$. 
To evaluate potential benefits of SRT2104 in severe experimental PH, we next tested effects of long-term SRT2104 treatment using a rat SuHx model of PH. SRT5416 or vehicle were administrated to male rats for five weeks starting at day 22 of SU5416 injection (gavage, five days/week) (Fig. 7a). Similar to human PAH and mouse PH (Figs. 1a, 6b), vehicle-treated rats with SuHxinduced PH developed VSM-specific Tsc2 deficiency in small remodeled PAs (Fig. 7b) that was associated with robust pulmonary vascular remodeling, PH, and RV hypertrophy (Fig. 7c-i). Importantly, treatment with SRT2104 restored Tsc2 in small PAs, reversed pulmonary vascular remodeling, normalized sRVP and PAP, and improved RV morphology and function (reversed RV hypertrophy and normalized max dP/dT and contractility index) (Fig. 7b-i). There were no significant differences in SLVP, MAP, and heart rate between SuHx+Vehicle and SuHx+SRT2104 groups (Fig. S8d-f). In aggregate, these data demonstrate that SRT2104 reverses established PH and improves RV morphology and function in a severe irreversible rat model of experimental $\mathrm{PH}$.

\section{Discussion}

The present study provides strong evidence that TSC2 deficiency in the medial layer of small PAs is an important trigger of pulmonary hypertension, and suggests that the restoration of functional TSC2 could be considered as a potentially attractive therapeutic strategy to reverse existing pulmonary vascular remodeling and PH. Our new findings are: (i) TSC2 is deficient in small remodeled PAs from subjects with $\mathrm{PAH}$, two models of experimental $\mathrm{PH}$, and early-passage PAVSMC derived from small PAs of PAH patients, and loss of TCS2 results in increased PAVSMC proliferation, survival, pulmonary vascular remodeling, and development of spontaneous PH; (ii) TSC2 in PAVSMC acts as a mechano-sensor and mechano-transducer and prevents up-regulation of YAP/TAZ, mTOR, and cell growth induced by pathological stiffness; (iii) TSC2 controls ECM composition, and its deficiency results in production of "diseased" ECM which up-regulates YAP/TAZ, mTOR, and induces growth of PAVSMC and PAAF; and (iv) pharmacological restoration of functional TSC2 by SRT2104 reverses molecular abnormalities, inhibits proliferation and induces apoptosis in human PAH PAVSMC, and reduces established pulmonary vascular remodeling and pulmonary hypertension in vivo in two models of experimental PH (Fig. 8).

Increased proliferation and resistance to apoptosis of pulmonary vascular cells in small PAs underline pulmonary vascular remodeling, a key component of PAH pathogenesis. Here, we show that TSC2, a key negative regulator of mTORC1 and cell growth (29), is deficient in proliferative PAVSMC and small remodeled PAs from human PAH lungs and in two rodent models of experimental PH. The key role of PAVSMC-specific TSC2 loss in pulmonary vascular remodeling is well supported by our in vitro and in vivo loss-of-function studies. Our data indicate that depletion of TSC2 induces unstimulated growth and proliferation of non-diseased human PAVSMC, and SMC-specific Tsc2 depletion in mice results in pulmonary vascular remodeling and early onset of spontaneous $\mathrm{PH}$, indicating that even partial depletion of smooth muscle Tsc 2 is sufficient to induce pulmonary vascular remodeling and pulmonary hypertension.

A switch to the hyper-proliferative, apoptosis-resistant PAVSMC phenotype could be induced by various pro-PH factors, including exposure to soluble mitogens and changes in the ECM composition and stiffness $(9,30,31)$. Intriguingly, we found that TSC2 in PAVSMC is predominantly 
regulated by the matrix stiffness and that TSC2 deficiency, induced by pathological matrix stiffening, is required for stiffness-induced growth of PAVSMC, suggesting that TSC2 acts as a mechanosensor and a mechanotransducer. Interestingly, in addition to the pathological stiffness, TSC2 was down-regulated, although to a lesser extent, by its canonical upstream inhibitor PDGF (29), suggestive of the multi-factorial nature of TSC2 regulation. Importantly, we found that TSC2 loss was required for the accumulation of pro-proliferative/pro-survival mechanotransducers YAP/TAZ, implicated in the pathogenesis of PAH $(8,12,32)$ and up-regulation of AktmTOR axis, indicating that TSC2 integrates mTOR and HIPPO networks, two major regulators of pulmonary vascular cell proliferation and survival in PAH (7-9, 33). Further, TSC2 is a welldescribed regulator of cellular metabolism, protein translation and autophagy, and loss or mutational inactivation of TSC2 in pulmonary LAM activates growth-promoting mTORC1, and upregulates RhoA GTPase and CDK2 (34), the pro-proliferative and vasoconstrictive molecules involved in PAH pathogenesis $(35,36)$. Although further studies are needed, it is possible that TSC2 in PAH acts as an integrator of mechanobiological cues with PAVSMC contractility, cellular metabolism, proliferative signaling and cell cycle progression. If this is the case, the TSC2 deficiency, observed by us in "diseased" PAVSMC, could explain the complex molecular reprograming seen in PAH pulmonary vasculature and may be responsible for both, vasoconstriction and pulmonary vascular remodeling, two major pathological features of PAH.

The proposed central role of TSC2 in pulmonary vascular remodeling is further supported by our findings that TSC2 modulates ECM production by PAVSMC. We demonstrate that TSC2 deficiency in PAVSMC leads to over-production of two major ECM components, fibronectin and collagen $1(8,37)$ and formation of the "diseased" ECM with PAH-specific properties. It is also important to note that decellularized matrix, produced by control PAVSMC with shRNAinduced TSC2 depletion, was able to induce growth of not only PAVSMC, but also PA adventitial fibroblasts, demonstrating a new role of TSC2 in modulating cell-cell communications in the pulmonary vasculature. Our findings are in good agreement with evidence highlighting the importance of cell-matrix and cell-cell communications in PAH pathogenesis (37) and suggest that TSC2 could be considered as an attractive molecular target to disrupt mechanotransduction via YAP and inhibit ECM remodeling and the associated proliferation of pulmonary vascular cells in PAH.

In the TSC2-deficient perivascular epithelioid tumors, YAP accumulation is induced by mTOR via impaired autophagosomal/lysosomal degradation (21). Our findings suggest the novel mechanism of TSC2-dependent YAP/TAZ and mTOR regulation via extracellular matrix and provide the link from TSC2 via extracellular fibronectin and integrin $\alpha 5 \beta 1$ to the PAVSMC growth response. Further, our observations that YAP negatively regulates TSC2 in an ECM-independent way provide evidence of the existence of negative intracellular TSC2-YAP cross-talk that supports unstimulated self-sustained proliferation and apoptosis resistance of PAVSMC in PAH.

Our study identifies TSC2 as an attractive molecular target, and SIRT1 activator SRT2104 as a potential therapeutic approach to restore TSC2 and reverse pulmonary vascular remodeling and pulmonary hypertension. Reconstitution of TSC2 by mammalian vector-induced expression fully normalized PAH-specific molecular abnormalities, ECM production, reduced abnormal growth and proliferation and induced apoptosis in human PAH PAVSMC. Similar effects were observed in human PAH PAVSMC treated with SIRT1 activator SRT2104. SIRT1 plays a protective role 
in systemic vasculature, reducing vascular ageing and atherosclerosis (38), and its activation improves systemic arterial vascular stiffness in smokers and subjects with type 2 diabetes. Mechanistically, SIRT1 stabilizes TSC2 via lysine deacetylation (24), preventing its degradation. We show that SRT2104 has a similar ability to reverse the diseased PAH PAVSMC phenotype, reduce proliferation and induce apoptosis via restoration of TSC2. Our in vivo data further support the potential attractiveness of SRT2104 as a therapeutic approach to treat PH. Orally administered SRT2104 restored smooth muscle Tsc2 in small PAs in two animal models of SuHxinduced PH. Importantly, even short-time (seven days) treatment of mice with already developed PH led to reduced pulmonary vascular remodeling, sRVP, and RV hypertrophy, the central clinical features of this disease. Further, longer treatment of rats with already established PH reversed pulmonary vascular remodeling, sRVP, Max dP/dT, and RV hypertrophy, and improved the RV contractility index, making TSC2 a promising target and SRT2104 a promising drug for therapeutic intervention.

In agreement with our findings, a polyphenol resveratrol which acts, at least in part, via activating SIRT1, prevented monocrotaline-induced PH in rats (39). Resveratrol, however, is extensively metabolized in humans, resulting in low systemic bioavailability and limited potential for therapeutic intervention (40). A rapamycin-based mTORC1 inhibitor, ABI009, is now in a clinical trial for patients with severe PAH (ClinicalTrials.gov Identifier: NCT02587325) and shows promising interim results (41); however, intravenous delivery and reported side effects could make use of this drug challenging for PAH patients. SIRT1 activator SRT2104 has an improved bioavailability, demonstrates benefits in pre-clinical models of age-related disorders (42), good tolerability in humans, a favorable selectivity profile (43), and has already entered clinical trials for type 2 diabetes and psoriasis $(44,45)$, which makes it an attractive candidate for clinical trials for patients with PAH.

We recognize that our study has several limitations. (1) One of the limitations is a small human sample size that arises from the nature of the studied disease. PAH is rare disease, which limits the availability of human lung tissue specimens and cells of early passage for mechanistic research of this type. However, the causal role of TSC2 deficiency in mediating PAVSMC hyperproliferation and pulmonary vascular remodeling in PAH is supported by the siRNA-mediated TSC2 depletion studies and studies of transgenic mice with SM-specific Tsc2 deficiency. (2) Not all in vitro experiments are designed using hydrogel matrices to model physiological or pathological stiffness. To separate stiffness-dependent TSC2 functions from its role in ECM remodeling and self-sustained proliferation and survival of PAH PAVSMC, several sets of data were collected from the cells cultured on plastic. While in agreement with our human tissuebased and hydrogels-derived data, the different substrate may affect a magnitude of observed molecular changes. (3) Because we didn't observe any differences between males and females in the SRT2104-treated SuHx mice, only male rats were evaluated in the rat SuHx model of PH. Finally, (4) rodent models of PH, can't completely recapitulate human PAH; the SRT2104 was given to the animals as a mono-treatment, and the combination of SRT2104 with currently used FDA-approved therapies is not evaluated. However, given our current findings in the cells from PAH subjects and transgenic mice, further testing of targeting TSC2 to reverse PAH is worthy of further investigation. 
Despite the major progress in PAH treatment within the past decade, there are still no curative options to reverse advanced disease. This is largely attributable to the multifactorial nature of this disease and complex molecular and metabolic reprograming of pulmonary vascular cells supported by cell-cell and cell-matrix interactions. Our finding that TSC2 links mechanobiological cues, growth factors and ECM signals with hyper-proliferation of PAVSMC and PAAF offers new options for therapeutic intervention. Our preclinical evidence show that SRT2104, which is already in clinical trials for other diseases and has a favorable safety profile (46), shows beneficial effects in human PAH PAVSMC and two rodent models of PH, warranting further assessment in other pre-clinical models of $\mathrm{PH}$ and clinical trials.

\section{Materials and Methods}

\section{Human Tissues and Cell Cultures}

Human lung tissues from unused donor (control) and idiopathic PAH patients were provided by the University of Pittsburgh Medical Center Lung Transplant, Pulmonary Division Tissue Donation under protocols approved by the University of Pittsburgh institutional review boards. Human primary distal PAVSMC, primary pulmonary adventitial fibroblasts (PAAF) and primary pulmonary arterial endothelial cells (PAEC) were provided by the Pulmonary Hypertension Breakthrough Initiative (PHBI) or by the University of Pittsburgh Vascular Medicine Institute (VMI) Cell Processing Core. Cell isolation, characterization and maintenance were performed under the rigorous and well-established study protocols adopted by the PHBI as described in (7, 8). Briefly, pre-capillary PAs were dissected out from the left lower lobe and adherent lung parenchymal tissue using microscissors and scalpel. The arteries were minced to $1 \mathrm{~mm}^{2}$ blocks, placed on the tissue culture plates with a small drop of LONZA culture medium (LONZA, Walkersville, MD) supplemented with SmGM-2 or FGM-2 media kit for PAVSMC and PAAF isolation, respectively $(7,8)$. On the following day, a full volume of respective full growth culture medium was added to the plates and left undisturbed for 3-5 days. The medium was then subsequently changed every other day until the cells reached confluence. PAVSMCs were characterized using antibodies against three smooth muscle-specific markers (smooth muscle $\alpha$-actin, smooth muscle myosin heavy chain, and SM22; Cell Signaling Technology, Danvers, MA) and cell morphology $(7,8)$. PAAFs were characterized using antibodies against vimentin, CD90, and negative staining for SM22, vWF, and cytokeratin (Cell Signaling Technology, Danvers, MA), to exclude contamination with smooth muscle, endothelial and epithelial cells, respectively (47). Primary cells (3-8 passage) of the same passage from a minimum of three control and three PAH subjects were used for each experimental condition. Cells and tissues from de-identified human subjects were used (please see Supplemental Table S1 for human subjects characteristics). All cells were maintained at $37{ }^{\circ} \mathrm{C}$ in a humidified incubator with $5 \% \mathrm{CO}_{2}$. For serum-deprivation, cells were maintained for 24-48hr in basal PromoCell medium (PromoCell, Heidelberg, Germany) supplemented with $0.1 \%$ bovine serum albumin (BSA) (Thermo Fisher Scientific, Waltham, MA). Softwell hydrogel-coated plates were purchased from Matrigen (Brea, CA) and used following the manufacturer's protocol.

Apoptosis analysis was performed using the In Situ Cell Death Detection Kit (Roche, Nutley, NJ) based on terminal deoxynucleotidyltransferase-mediated dUTP-biotin nick end labeling (TUNEL) technology according to the manufacturer's protocol as previously described in $(7,8$, 48). Nuclei were detected by 4',6-diamidino-2-phenylindole (DAPI) (Invitrogen, Carlsbad, CA). 
Images were captured by an All-in-One Fluorescence Microscope BZ-X810 (Keyence, Itasca, IL); blind semi-automatic counts were performed. A minimum of 200 cells were counted per each condition in each experiment.

Cell proliferation was examined using DNA synthesis analysis (bromodeoxyuridine (BrdU) incorporation assay) or Ki67 detection with specific antibody (Cell Signaling Technology, Danvers, MA) as described previously $(7,8,48,49)$. For the BrdU incorporation assay, cells, serumdeprived for 48 hours, were incubated with $10 \mu \mathrm{M}$ BrdU (Abcam, Cambridge, MA) for 18 hours, fixed with 4\% paraformaldehyde in PBS (Santa Cruz Biotechnology, Dallas, TX), permeabilized by $2 \mathrm{M} \mathrm{HCl}$, and stained with anti-BrdU antibody (BD Biosciences, San Jose, CA). Staining with DAPI and anti-GFP antibody (Cell Signaling Technology, Danvers, MA) was performed to detect nuclei and GFP, respectively. For Ki67 detection, staining with anti-Ki67 antibody and DAPI was performed. Images were taken using an All-in-One Fluorescence Microscope BZX810 (Keyence, Itasca, IL); blinded semi-automatic analysis was performed. The cell proliferation was evaluated as the percentage of BrdU-positive or Ki67-positive cells per total number of cells. A minimum of 200 cells were counted in each experiment per each condition.

Cell growth analysis was performed as described previously in $(7,8,48)$. Briefly, cells, treated with ATN-161 (MCE LLC, Monmouth Junction, NJ), BTT-3033 (R\&D Systems, Minneapolis, MN), SRT2104 (InvivoChem, Libertyville, IL), or an appropriate diluent were trypsinized and resuspended in the same volume of basal medium supplemented with $0.1 \%$ BSA. Cell counts were performed using the Countess II FL Automated Cell Counter (Thermo Fisher Scientific, Waltham, MA).

Immunohistochemical, Immunocytochemical and Immunoblot Analyses were performed as described in $(7,8,19,50)$. Images were captured with an Olympus FV1000 Confocal Microscope (Olympus America Inc., Central Valley, PA) or the All-in-One Fluorescence Microscope BZ-X810 (Keyence, Itasca, IL). Immunoblot signals were captured with HyBlot CL® Autoradiography Films (Thomas Scientific, Swedesboro, NJ), and fixed and developed by Medical Film Processor (Konica Minolta, Ramsey, NJ). Immunoblots and immunostainings OD were analyzed using ImageJ (NIH, Bethesda, MD). Antibodies for TSC2 (\#4308), Cleaved Caspase-3 (Asp175) (\#9661), GFP (\#2956), phospho-Ser235/236-S6 (\#4856), S6 (\#2217), YAP/TAZ (\#8418), $\alpha / \beta$ Tubulin (\#2148), phospho-Ser473-Akt (\#4060), Akt (\#9272), and anti-rabbit IgG-HRP-linked antibody (\#7074) were purchased from Cell Signaling Technology (Danvers, MA); antifibronectin antibody (ab2413) was purchased from Abcam (Cambridge, MA); anti-collagen1A1 antibody (AF6220) was purchased from R\&D Systems (Minneapolis, MN); anti-actin, and $\alpha$ smooth muscle-FITC antibody (F3777) were purchased from Sigma-Aldrich (St. Louis, MO); Alexa Fluor 488, 594 and 647 dyes and rabbit anti-sheep IgG-HRP-linked antibody (\#61-8620) were purchased from Thermo Fisher Scientific (Waltham, MA).

Transfection, Infection, and de-cellularization were performed as described previously in (7, 8, 51). The p-EGFP plasmid (\#6077-1) was purchased from Addgene (Watertown, MA); the pEGFP-TSC2 plasmid was created as previously described in $(52,53)$. siRNAs and shRNAs were purchased from Dharmacon (PerkinElmer, Waltham, MA) and Santa Cruz Biotechnology (Dallas, TX), respectively. siRNA transfection and shRNA infection were performed according to the manufacturers' protocols. The Effectene transfection reagent (Qiagen, Valencia, CA) was 
used following the manufacturer's protocol. For the production of decellularized matrices, preconfluent PAVSMC were maintained on the plastic plates for six days, and then decellularization was performed.

Animals. All animal procedures were performed under the protocols approved by the Animal Care and Use Committees of the University of Pittsburgh and the University of California, Davis.

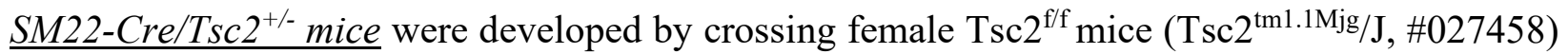
with male SM22-Cre mice (B6.Cg-Tg(Tagln-cre)1Her/J, \#017491) (Jackson Laboratory, Bar Harbor, ME) carrying mouse smooth muscle protein 22-alpha (SM22) promoter inducing Cre recombinase expression selectively in the $\operatorname{VSMC}(54,55)$. Nine weeks-old animals were subjected to hemodynamic and morphological analysis as described below. All mice were genotyped prior to experiments. The genotyping of the DNA extracted from ears of transgenic mice by Extract-N-Amp ${ }^{\text {TM }}$ Tissue PCR Kit (Sigma St. Louis, MO) was performed following the manufacturer's protocol. Polymerase chain reaction (PCR) samples were prepared using KAPA2G Fast PCR Kit (Sigma St. Louis, MO) following the manufacturer's protocol. SM22-Cre gene was detected by Cre primers (Cre-R: 5'-GCAATTTCGGCTATACGTAACAGGG; Cre-F: 5'GCAAGAACCTGATGGACATGTTCAG) with internal control primers (oIMR7338: 5'CTAGGCCACAGAATTGAAAGATCT; oIMR7339: 5'-GTAGGTGGAAATTCTAGCATCC). Tsc2 gene was detected by Tsc2 primers (Tsc2-F: 5'-ACAATGGGAGGCACATTACC; Tsc2-R: 5'-AAGCAGCAGGTCTGCAGTG). All primers were purchased from Sigma (St. Louis, MO). Controls were same-age same-sex mice of the same background (C57BL/6J, Jackson Laboratories, Bar Harbor, ME) housed in the same conditions $(8,56,57)$.

In vivo experimental $P H$ was induced by SU5416/hypoxia as described previously in $(7,8,49)$. Mice: Six- to eight-week-old male and female C57BL/6J mice were exposed to hypoxia (10\% $\mathrm{O}_{2}$ ) up to 35 days; subcutaneous injections of SU5416 (20 mg/kg) (Tocris, Minneapolis, MN) were performed at days 0, 7, and 14 of the experiment. At days 15-21 after PH induction, SRT2104 (InvivoChem, Libertyville, IL) suspended in the warm corn oil (ACROS Organics, Fair Lawn, NJ) $(100 \mathrm{mg} / \mathrm{kg} /$ day, oral gavage, $200 \mu \mathrm{L} / \mathrm{mouse})$ or warm corn oil alone were administrated daily. Both male and female mice were used; controls were same-age same-sex mice maintained under normoxia. Rats: Six- to eight-week-old male Sprague-Dawley rats (Charles River Laboratories, Wilmington, MA) received a single dose of SU5416 (sq $20 \mathrm{mg} / \mathrm{kg}$ ) and were then maintained for three weeks under hypoxia $\left(10 \% \mathrm{O}_{2}\right)$ and for five weeks under normoxia. SRT2104 (InvivoChem, Libertyville, IL) was (ACROS Organics, Fair Lawn, NJ); SRT2104 and vehicle (warm corn oil alone) were administrated starting at the beginning of the week four of the experiment for five weeks $(100 \mathrm{mg} / \mathrm{kg} /$ day, oral gavage, five days/week). Negative controls were normoxia-maintained age-matched animals. The volume of the vehicle was equal for the volume of SRT2104 suspension $(200 \mu \mathrm{L} /$ mouse or $3 \mathrm{~mL} / \mathrm{rat})$. After terminal hemodynamic analysis, animals were euthanized, and lung and heart tissues were collected for morphological analysis. Hearts were separated into right ventricle (RV) and left ventricle (LV)+Septum, and the Fulton index was calculated as $\mathrm{RV} /(\mathrm{LV}+\mathrm{Septum})$ ratio.

Hemodynamic analysis was performed as described in $(8,49,57,58)$. Briefly, animals were anesthetized by isoflurane (Minrad Inc., Orchard Park, NY) (5\% for induction, 2\% during surgery, $1 \%$ while performing PV loop measurements), and in vivo pressure-volume PV loop measurements were performed by PV catheters (Scisense, Inc., London, ON, Canada). The catheter, attached to the data acquisition system (EMKA Instruments, Falls Church, VA) was inserted into 
the RV and then into the LV; data were acquired by the ADVantage PV System (Transonic Systems Inc., Ithaca, NY) and IOX2 software (EMKA Technologies Inc., Falls Church, VA). PAP was calculated as a sRVP $\times 0.65+0.55 \mathrm{mmHg}(49,59)$. MAP was calculated as $\mathrm{SLVP} \times 0.65+0.55$ $\mathrm{mmHg}(49,59)$; RV contractility index was calculated as (Max dP/dT)/sRVP s${ }^{-1}(49,60)$.

Morphological and immunohistological analyses were performed as described previously in (7, $8,19,48,49,58,61)$. Briefly, after being perfused by PBS via PA, lungs were filled with $80 \%$ Tissue Plus OCT Compound (Fisher Scientific, Hampton, NH)/20\% saline solution, snap frozen in dry ice and kept at $-80^{\circ} \mathrm{C}$, or fixed in $4 \%$ paraformaldehyde solution in PBS and embedded in paraffin. After sectioning, lung tissue slides ( $5 \mu \mathrm{m}$ thickness) were stained by H\&E or immunostained to detect Tsc2, smooth muscle $\alpha$-actin (SMA) and nuclei (DAPI) (Invitrogen, Carlsbad, CA) as previously described in $(7,8)$. Images for PA MT calculation were captured from blindselected small PAs $(25-100 \mu \mathrm{m}$ outer diameter; a minimum of six animals/group, a minimum of $12 \mathrm{PAs} /$ animal) of H\&E- or SMA-stained rodent's lung tissues and calculated using the VMI Calculator (61). The whole H\&E-stained rat's lung tissue sections were captured (6 rats/group, minimum of $29 \mathrm{PAs} /$ rat) to count percentage of fully (grade 2), partially (grade 1), and nonoccluded (grade 0$)$ small (25-50 $\mu$ m outer diameter) PAs $(8,58,61-63)$. Images were taken with an All-in-One Fluorescence Microscope BZ-X810.

Statistical Analysis was performed using STATA software (StataCorp, College Station, TX) software. Statistical comparisons between two groups were performed by the Mann-Whitney U test (64) (significance p-value less than 0.05 ); in vitro data statistical comparisons among 3 or more groups were performed by the Kruskal-Wallis test with Dunn's Pairwise Comparison (65, 66) (significance p-value less than 0.025); in vivo data statistical comparisons among 3 groups were performed by the Analysis of Variance (ANOVA) test; the differences between PH or control group and other groups were analyzed by planned comparisons (67) (significance $p$-value less than 0.05).

\section{Supplementary Materials}

Fig. S1. TSC2 protein levels are not reduced in PAAF or PAEC from PAH lungs compared to controls.

Fig. S2. Tcs2 protein reduction in SMA-positive areas in small PAs from SM22-Tsc ${ }^{+/}$mice.

Fig. S3. ECM produced by human PAH PAVSMC promotes YAP/TAZ accumulation, increases phosphorylation of Akt and S6 in control PAVSMC.

Fig. S4. YAP depletion in human PAH PAVSMC results in TSC2 accumulation.

Fig. S5. Pharmacological inhibition of mTOR has no significant effect on TSC2 and YAP/TAZ protein levels in human PAH PAVSMC.

Fig. S6. (a) TSC2 reduces Collagen 1 levels in human PAH PAVSMC. (b) BrdU incorporation in human PAH PAVSMC expressing GFP and GFP-TSC2.

Fig. S7. TSC2 protein levels in human PAH PAVSMC treated with the Akt inhibitor and AICAR.

Fig. S8. SRT2104 does not affect systemic pressure and heart rate of mice and rats with SuHxinduced $\mathrm{PH}$. 
Table S1. Human subjects' characteristics.

\section{References and Notes:}

1. Humbert M, Morrell NW, Archer SL, Stenmark KR, MacLean MR, Lang IM, Christman BW, Weir EK, Eickelberg O, Voelkel NF, Rabinovitch M. Cellular and molecular pathobiology of pulmonary arterial hypertension. Journal of the American College of Cardiology 2004; 43: S13-S24.

2. Hyduk A, Croft JB, Ayala C, Zheng K, Zheng ZJ, Mensah GA. Pulmonary Hypertension Surveillance --- United States, 1980--2002. MMWR Surveillance Summaries 2005: 1-28.

3. George MG, Schieb LJ, Ayala C, Talwalkar A, Levant S. Pulmonary hypertension surveillance: United states, 2001 to 2010. Chest 2014; 146: 476-495.

4. Frost AE, Badesch DB, Barst RJ, Benza RL, Elliott CG, Farber HW, Krichman A, Liou TG, Raskob GE, Wason P, Feldkircher K, Turner M, McGoon MD. The Changing Picture of Patients With Pulmonary Arterial Hypertension in the United States. Chest 2011; 139: 128-137.

5. Guignabert C, Tu L, Le Hiress M, Ricard N, Sattler C, Seferian A, Huertas A, Humbert M, Montani D. Pathogenesis of pulmonary arterial hypertension: lessons from cancer. European Respiratory Review 2013; 22: 543-551.

6. Morrell NW, Adnot S, Archer SL, Dupuis J, Jones PL, MacLean MR, McMurtry IF, Stenmark KR, Thistlethwaite PA, Weissmann N, Yuan JXJ, Weir EK. Cellular and Molecular Basis of Pulmonary Arterial Hypertension. Journal of the American College of Cardiology 2009; 54: S20-S31.

7. Goncharov DA, Kudryashova TV, Ziai H, Ihida-Stansbury K, DeLisser H, Krymskaya VP, Tuder RM, Kawut SM, Goncharova EA. Mammalian target of rapamycin complex 2 (mTORC2) coordinates pulmonary artery smooth muscle cell metabolism, proliferation, and survival in pulmonary arterial hypertension. Circulation 2014; 129: 864-874.

8. Kudryashova TV, Goncharov DA, Pena A, Kelly N, Vanderpool R, Baust J, Kobir A, Shufesky W, Mora AL, Morelli AE, Zhao J, Ihida-Stansbury K, Chang B, DeLisser H, Tuder RM, Kawut SM, Silljé HHW, Shapiro S, Zhao Y, Goncharova EA. HIPPOIntegrin-linked Kinase Cross-Talk Controls Self-Sustaining Proliferation and Survival in Pulmonary Hypertension. American Journal of Respiratory and Critical Care Medicine 2016; 194: 866-877.

9. Pullamsetti SS, Savai R, Seeger W, Goncharova EA. Translational Advances in the Field of Pulmonary Hypertension.From Cancer Biology to New Pulmonary Arterial Hypertension Therapeutics. Targeting Cell Growth and Proliferation Signaling Hubs. American Journal of Respiratory and Critical Care Medicine 2017; 195: 425-437.

10. Masri FA, Xu W, Comhair SAA, Asosingh K, Koo M, Vasanji A, Drazba J, Anand-Apte B, Erzurum SC. Hyperproliferative apoptosis-resistant endothelial cells in idiopathic pulmonary arterial hypertension. American Journal of Physiology: Lung Cellular and Molecular Physiology 2007; 293: L548-L554.

11. Bertero T, Cottrill KA, Annis S, Bhat B, Gochuico BR, Osorio JC, Rosas I, Haley KJ, Corey KE, Chung RT, C.B. N, Chan SY. A YAP/TAZ-miR-130/301 molecular circuit exerts systems-level control of fibrosis in a network of human diseases and physiologic conditions. Scientific Reports 2015; 5: 18277. 
12. Bertero T, Oldham WM, Cottrill KA, Pisano S, Vanderpool RR, Yu Q, Zhao J, Tai Y, Tang Y, Zhang Y-Y, Rehman S, Sugahara M, Qi Z, Gorcsan JI, Vargas SO, Saggar R, Saggar R, Wallace WD, Ross DJ, Haley KJ, Waxman AB, Parikh VN, De Marco T, Hsue PY, Morris A, Simon MA, Norris KA, Gaggioli C, Loscalzo J, Fessel J, Chan SY. Vascular stiffness mechanoactivates YAP/TAZ-dependent glutaminolysis to drive pulmonary hypertension. The Journal of Clinical Investigation 2016; 126: 3313-3335.

13. Savai R, Al-Tamari HM, Sedding D, Kojonazarov B, Muecke C, Teske R, Capecchi MR, Weissmann N, Grimminger F, Seeger W, Schermuly RT, Pullamsetti SS. Proproliferative and inflammatory signaling converge on FoxO1 transcription factor in pulmonary hypertension. Nature Medicine 2014; 20: 1289-1300.

14. Bertero T, Cottrill KA, Lu Y, Haeger CM, Dieffenbach P, Annis S, Hale A, Bhat B, Kaimal V, Zhang Y-Y, Graham BB, Kumar R, Saggar R, Saggar R, Wallace WD, Ross DJ, Black SM, Fratz S, Fineman JR, Vargas SO, Haley KJ, Waxman AB, Chau BN, Fredenburgh LE, Chan SY. Matrix remodeling promotes pulmonary hypertension through feedback mechanoactivation of the YAP/TAZ-miR-130/301 circuit. Cell Reports 2015; 13: 1016-1032.

15. Liu F, Haeger CM, Dieffenbach PB, Sicard D, Chrobak I, Coronata AMF, Velandia MMS, Vitali S, Colas RA, Norris PC, Marinković A, Liu X, Ma J, Rose CD, Lee S-J, Comhair SAA, Erzurum SC, McDonald JD, Serhan CN, Walsh SR, Tschumperlin DJ, Fredenburgh LE. Distal vessel stiffening is an early and pivotal mechanobiological regulator of vascular remodeling and pulmonary hypertension. JCI Insight 2016; 1.

16. Krymskaya VP, Goncharova EA. PI3K/mTORC1 activation in hamartoma syndromes: therapeutic prospects. Cell Cycle 2009; 8: 403-413.

17. Huang J, Manning BD. The TSC1-TSC2 complex: a molecular switchboard controlling cell growth. Biochemical Journal 2008; 412: 179-190.

18. Huynh H, Hao H-X, Chan SL, Chen D, Ong R, Soo KC, Pochanard P, Yang D, Ruddy D, Liu M, Derti A, Balak MN, Palmer MR, Wang Y, Lee BH, Sellami D, Zhu AX, Schlegel R, Huang A. Loss of Tuberous Sclerosis Complex 2 (TSC2) Is Frequent in Hepatocellular Carcinoma and Predicts Response to mTORC1 Inhibitor Everolimus. Molecular Cancer Therapeutics 2015; 14: 1224-1235.

19. Krymskaya VP, Snow J, Cesarone G, Khavin I, Goncharov DA, Lim PN, Veasey SC, IhidaStansbury K, Jones PL, Goncharova EA. mTOR is required for pulmonary arterial vascular smooth muscle cell proliferation under chronic hypoxia. The FASEB Journal 2011; 25: 1922-1933.

20. Houssaini A, Abid S, Mouraret N, Wan F, Rideau D, Saker M, Marcos E, Tissot C-M, Dubois-Randé J-L, Amsellem V, Adnot S. Rapamycin Reverses Pulmonary Artery Smooth Muscle Cell Proliferation in Pulmonary Hypertension. American Journal of Respiratory Cell and Molecular Biology 2013; 48: 568-577.

21. Liang N, Zhang C, Dill P, Panasyuk G, Pion D, Koka V, Gallazzini M, Olson EN, Lam H, Henske EP, Dong Z, Apte U, Pallet N, Johnson RL, Terzi F, Kwiatkowski DJ, Scoazec JY, Martignoni G, Pende M. Regulation of YAP by mTOR and autophagy reveals a therapeutic target of tuberous sclerosis complex. Journal of Experimental Medicine 2014; 211: 2249-2263.

22. Houssaini A, Abid S, Derumeaux G, Wan F, Parpaleix A, Rideau D, Marcos E, Kebe K, Czibik G, Sawaki D, Treins C, Dubois-Randé J-L, Li Z, Amsellem V, Lipskaia L, Pende M, Adnot S. Selective Tuberous Sclerosis Complex 1 Gene Deletion in Smooth Muscle 
Activates Mammalian Target of Rapamycin Signaling and Induces Pulmonary Hypertension. American Journal of Respiratory Cell and Molecular Biology 2016; 55 : 352-367.

23. Cottin V, Harari S, Humbert M, Mal H, Dorfmüller P, Jaïs X, Reynaud-Gaubert M, Prevot G, Lazor R, Taillé C, Lacronique J, Zeghmar S, Simonneau G, Cordier J-F, Cottin V, Zeghmar S, Cordier J-F, Harari S, Humbert M, Jaïs X, Simonneau G, Mal H, Taillé C, Dorfmüller P, Reynaud-Gaubert M, Prevot G, Lacronique J, Lazor R. Pulmonary hypertension in lymphangioleiomyomatosis: characteristics in 20 patients. European Respiratory Journal 2012; 40: 630-640.

24. García-Aguilar A, Guillén C, Nellist M, Bartolomé A, Benito M. TSC2 N-terminal lysine acetylation status affects to its stability modulating mTORC1 signaling and autophagy. Biochimica et Biophysica Acta (BBA) - Molecular Cell Research 2016; 1863: 2658-2667.

25. Tang H, Chen J, Fraidenburg DR, Song S, Sysol JR, Drennan AR, Offermanns S, Ye RD, Bonini MG, Minshall RD, Garcia JG, Machado RF, Makino A, Yuan JX. Deficiency of Akt1, but not Akt2, Attenuates the Development of Pulmonary Hypertension. American Journal of Physiology: Lung Cellular and Molecular Physiology 2014; Epub ahead of print.

26. Nagata D, Takeda R, Sata M, Satonaka H, Suzuki E, Nagano T, Hirata Y. AMP-Activated Protein Kinase Inhibits Angiotensin II-Stimulated Vascular Smooth Muscle Cell Proliferation. Circulation 2004; 110: 444-451.

27. Rubin LJ, Magliola L, Feng X, Jones AW, Hale CC. Metabolic activation of AMP kinase in vascular smooth muscle. Journal of Applied Physiology 2005; 98: 296-306.

28. Shackelford DB, Shaw RJ. The LKB1-AMPK pathway: metabolism and growth control in tumour suppression. Nature Reviews Cancer 2009; 9: 563-575.

29. Goncharova EA, Krymskaya VP. Pulmonary lymphangioleiomyomatosis (LAM): Progress and current challenges. Journal of Cellular Biochemistry 2008; 103: 369-382.

30. Stenmark KR, Mecham RP. CELLULAR AND MOLECULAR MECHANISMS OF PULMONARY VASCULAR REMODELING. Annual Review of Physiology 1997; 59: 89-144.

31. Sun W, Chan SY. Pulmonary Arterial Stiffness: An Early and Pervasive Driver of Pulmonary Arterial Hypertension. Frontiers in Medicine (Lausanne) 2018; 5: 204-204.

32. Dieffenbach PB, Haeger CM, Coronata AMF, Choi KM, Varelas X, Tschumperlin DJ, Fredenburgh LE. Arterial stiffness induces remodeling phenotypes in pulmonary artery smooth muscle cells via YAP/TAZ-mediated repression of cyclooxygenase-2. American Journal of Physiology: Lung Cellular and Molecular Physiology 2017; 313: L628-1647.

33. DeFelice A, Stewart D, Walker G, Truebel H, Stenmark K, Rabinovitch M, Fiszman M, Saulnier M, Morrell N, Schermuly R, Archer S, Evans S, Martin T. Anticipated classes of new medications and molecular targets for pulmonary arterial hypertension. Pulmonary Circulation 2013; 3:226-244.

34. Goncharova EA, Goncharov DA, Eszterhas A, Hunter DS, Glassberg MK, Yeung RS, Walker CL, Noonan D, Kwiatkowski DJ, Chou MM, Panettieri RA, Krymskaya VP. Tuberin regulates p70 S6 kinase activation and ribosomal protein S6 phosphorylation: a role for the TSC2 tumor suppressor gene in pulmonary lymphangioleiomyomatosis. The Journal of Biological Chemistry 2002; 277: 30958-30967.

35. Weiss A, Neubauer MC, Yerabolu D, Kojonazarov B, Schlueter BC, Neubert L, Jonigk D, Baal N, Ruppert C, Dorfmuller P, Pullamsetti SS, Weissmann N, Ghofrani H-A, 
Grimminger F, Seeger W, Schermuly RT. Targeting cyclin-dependent kinases for the treatment of pulmonary arterial hypertension. Nature Communications 2019; 10: 2204.

36. Barman SA, Zhu S, White RE. RhoA/Rho-kinase signaling: a therapeutic target in pulmonary hypertension. Vascular Health and Risk Management 2009; 5: 663-671.

37. Thenappan T, Chan SY, Weir EK. Role of extracellular matrix in the pathogenesis of pulmonary arterial hypertension. American Journal of Physiology - Heart and Circulatory Physiology 2018; 315: H1322-H1331.

38. Bonkowski MS, Sinclair DA. Slowing ageing by design: the rise of NAD+ and sirtuinactivating compounds. Nature Reviews Molecular Cell Biology 2016; 17: 679-690.

39. Csiszar A, Labinskyy N, Olson S, Pinto JT, Gupte S, Wu JM, Hu F, Ballabh P, Podlutsky A, Losonczy G, de Cabo R, Mathew R, Wolin MS, Ungvari Z. Resveratrol Prevents Monocrotaline-Induced Pulmonary Hypertension in Rats. Hypertension 2009; 54: 668675.

40. Knutson MD, Leeuwenburgh C. Resveratrol and novel potent activators of Sirt1: effects on aging and age-related diseases. Nutrition Reviews 2008; 66: 591-596.

41. Simon M, Gomberg-Maitland M, Oudiz R, Machado R, Rischard F, Elinoff J, Grigorian B, Schmid A, Hou S, Desai N, Gladwin M. PATIENTS WITH SEVERE PULMONARY ARTERIAL HYPERTENSION TREATED WITH ABI-009, NAB-SIROLIMUS, AN MTOR INHIBITOR: INTERIM RESULTS FROM A PHASE 1 CLINICAL TRIAL. Journal of the American College of Cardiology 2019; 73: 1927-1927.

42. Zhang X, Li X, Zhang J. Current Status and Future Perspectives of PI3K and mTOR Inhibitor as Anticancer Drugs in Breast Cancer. Current Cancer Drug Targets 2013; 13: 175-187.

43. Hoffmann E, Wald J, Lavu S, Roberts J, Beaumont C, Haddad J, Elliott P, Westphal C, Jacobson E. Pharmacokinetics and tolerability of SRT2104, a first-in-class small molecule activator of SIRT1, after single and repeated oral administration in man. British Journal of Clinical Pharmacology 2013; 75: 186-196.

44. Venkatasubramanian S, Noh RM, Daga S, Langrish JP, Mills NL, Waterhouse BR, Hoffmann E, Jacobson EW, Lang NN, Frier BM, Newby DE. Effects of the small molecule SIRT1 activator, SRT2104 on arterial stiffness in otherwise healthy cigarette smokers and subjects with type 2 diabetes mellitus. Open Heart 2016; 3: e000402.

45. Baksi A, Kraydashenko O, Zalevkaya A, Stets R, Elliott P, Haddad J, Hoffmann E, Vlasuk GP, Jacobson EW. A phase II, randomized, placebo-controlled, double-blind, multi-dose study of SRT2104, a SIRT1 activator, in subjects with type 2 diabetes. British Journal of Clinical Pharmacology 2014; 78: 69-77.

46. Krueger JG, Suárez-Fariñas M, Cueto I, Khacherian A, Matheson R, Parish LC, Leonardi C, Shortino D, Gupta A, Haddad J, Vlasuk GP, Jacobson EW. A Randomized, PlaceboControlled Study of SRT2104, a SIRT1 Activator, in Patients with Moderate to Severe Psoriasis. PLOS ONE 2015; 10: e0142081.

47. Wang D, Zhang H, Li M, Frid MG, Flockton AR, McKeon BA, Yeager ME, Fini MA, Morrell NW, Pullamsetti SS. MicroRNA-124 controls the proliferative, migratory, and inflammatory phenotype of pulmonary vascular fibroblasts. Circulation Research 2014; 114: 67-78.

48. Goncharova EA, Goncharov DA, Li H, Pimtong W, Lu S, Khavin I, Krymskaya VP. mTORC2 Is Required for Proliferation and Survival of TSC2-Null Cells. Molecular and Cellular Biology 2011; 31: 2484-2498. 
49. Shen Y, Goncharov DA, Avolio T, Ray A, Okorie E, DeLisser H, Mora AL, Vanderpool R, Kudryashova TV, Goncharova EA. Differential effects of integrin-linked kinase inhibitor $\mathrm{Cpd} 22$ on severe pulmonary hypertension in male and female rats. Pulmonary Circulation 2020; 10: 2045894019898593.

50. Goncharova EA, Goncharov DA, Krymskaya VP. Assays for in vitro monitoring of human airway smooth muscle (ASM) and human pulmonary arterial vascular smooth muscle (VSM) cell migration. Nature Protocols 2007; 1: 2933-2939.

51. Parmaksiz M, Elçin AE, Elçin YM. Decellularized Cell Culture ECMs Act as Cell Differentiation Inducers. Stem Cell Reviews and Reports 2020; 16: 569-584.

52. Goncharova E, Goncharov D, Noonan D, Krymskaya VP. TSC2 modulates actin cytoskeleton and focal adhesion through TSC1-binding domain and the Rac1 GTPase. The Journal of Cell Biology 2004; 167: 1171-1182.

53. Finlay GA, York B, Karas RH, Fanburg BL, Zhang H, Kwiatkowski DJ, Noonan DJ. Estrogen-induced smooth muscle cell growth is regulated by tuberin and associated with altered activation of platelet-derived growth factor receptor-beta and ERK-1/2. The Journal of Biological Chemistry 2004; 279: 23114-23122.

54. Lesche R, Groszer M, Gao J, Wang Y, Messing A, Sun H, Liu X, Wu H. Cre/loxP-mediated inactivation of the murine Pten tumor suppressor gene. genesis 2002; 32: 148-149.

55. Schwenk F, Baron U, Rajewsky K. A cre-transgenic mouse strain for the ubiquitous deletion of loxP-flanked gene segments including deletion in germ cells. Nucleic Acids Research 1995; 23: 5080.

56. Meloche J, Pflieger A, Vaillancourt M, Paulin R, Potus F, Zervopoulos S, Graydon C, Courboulin A, Breuils-Bonnet S, Tremblay È, Couture C, Michelakis ED, Provencher S, Bonnet S. Role for DNA Damage Signaling in Pulmonary Arterial Hypertension. Circulation 2014; 129: 786-797.

57. Taraseviciene-Stewart L, Kasahara Y, Alger L, Hirth P, Mc Mahon G, Walrenberfer J, Voelkel NF, Tuder RM. Inhibition of the VEGF receptor 2 combined with chronic hypoxia causes cell death-dependent pulmonary endothelial cell proliferation and severe pulmonary hypertension. The FASEB Journal 2001; 15: 427-438.

58. Pena A, Kobir A, Goncharov D, Goda A, Kudryashova TV. Pharmacological Inhibition of mTOR Kinase Reverses Right Ventricle Remodeling and Improves Right Ventricle Structure and Function in Rats. American Journal of Respiratory Cell and Molecular Biology 2017; 57: 615-625.

59. Syyed R, Reeves JT, Welsh D, Raeside D, Johnson MK, Peacock AJ. The relationship between the components of pulmonary artery pressure remains constant under all conditions in both health and disease. Chest 2008; 133: 633-639.

60. MASON DT, Braunwald E, COVELL JW, SONNENBLICK EH, ROSS JR J. Assessment of cardiac contractility: the relation between the rate of pressure rise and ventricular pressure during isovolumic systole. Circulation 1971; 44: 47-58.

61. Kelley EE, Baust J, Bonacci G, Golin-Bisello F, Devlin JE, St. Croix CM, Watkins SC, Gor S, Cantu-Medellin N, Weidert ER, Frisbee JC, Gladwin MT, Champion HC, Freeman BA, Khoo NKH. Fatty acid nitroalkenes ameliorate glucose intolerance and pulmonary hypertension in high-fat diet-induced obesity. Cardiovascular Research 2014; 101: 352363. 
62. Oka M, Homma N, Taraseviciene-Stewart L, Morris KG, Kraskauskas D, Burns N, Voelkel NF, McMurtry IF. Rho kinase-mediated vasoconstriction is important in severe occlusive pulmonary arterial hypertension in rats. Circulation Research 2007; 100: 923-929.

63. Gairhe S, Joshi SR, Bastola MM, McLendon JM, Oka M, Fagan KA, McMurtry IF. Sphingosine-1-phosphate is involved in the occlusive arteriopathy of pulmonary arterial hypertension. Pulmonary Circulation 2016; 6: 369-380.

64. Mann HB, Whitney DR. On a test of whether one of two random variables is stochastically larger than the other. The Annals of Mathematical Statistics 1947: 50-60.

65. Dinno A. Nonparametric pairwise multiple comparisons in independent groups using Dunn's test. The Stata Journal 2015; 15: 292-300.

66. Kruskal WH, Wallis WA. Use of ranks in one-criterion variance analysis. Journal of the American statistical Association 1952; 47: 583-621.

67. Beasley TM, Schumacker RE. Multiple regression approach to analyzing contingency tables: Post hoc and planned comparison procedures. The Journal of Experimental Education 1995; 64: 79-93.

Acknowledgements: We thank Andrea Sebastiani and the Small Animal Hemodynamic Core at the University of Pittsburgh Heart, Lung, and Blood Vascular Medicine Institute (VMI) for acquisition and analysis of animal hemodynamic data. We thank Pulmonary Hypertension Breakthrough Initiative (PHBI) and the University of Pittsburgh VMI Cell processing Core for providing lung tissues and pulmonary vascular cells from patients with PAH and unused donor lungs. We thank John Sembrat from the University of Pittsburgh School of Medicine for his help with acquisition of human tissues.

Funding: This work is supported by NIH/NHLBI R01HL113178 (EAG), R01HL130261 (EAG), R01HL150638 (EAG), 5P01HL103455-05 (ALM, EAG), 1 U01HL145550 (MR), 5 P50AR060780 (MR), and American Heart Association Postdoctoral Fellowship 826806 (YS). The Pulmonary Hypertension Breakthrough 13 Initiative is supported by NIH/NHLBI R24HL123767.

Author contributions: Y.S., D.A.G., A.P., J.B., A.C.B., A.R., A.R., B.C., M.R., T.V.K., and E.A.G. acquired the data. Y.S., D.A.G., A.P., B.C., T.N.B., H.D., A.L.M., M.R., T.V.K., and E.A.G. analyzed and interpreted the data. Y.S. and E.A.G. conceived and designed research. H.D. contributed human pulmonary vascular cells. Y.S., H.D., A.M.L. and E.A.G. drafted and edited the manuscript.

Competing interests: the authors declare no competing interests.

Data and materials availability: The data are available from the corresponding authors on reasonable request. The materials are available via standard MTA process. 
Figure 1. TSC2 deficiency results in the increased PAVSMC proliferation, vascular remodeling and PH (see also Supplemental Figs. S1 and S2 for additional data)

\section{Human PAs}
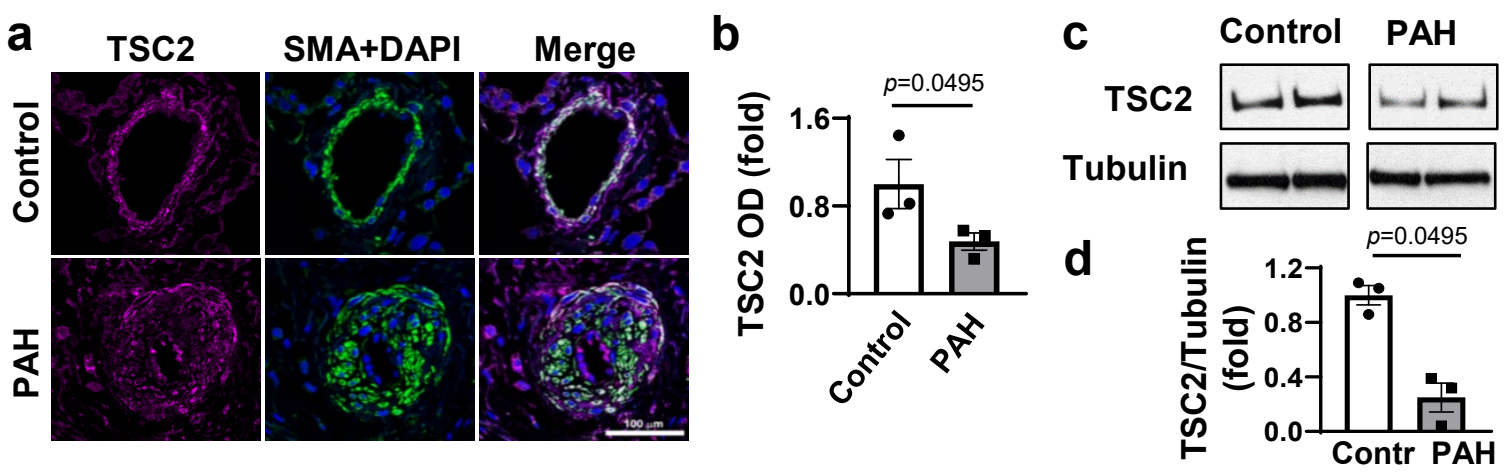

\section{Human PAVSMC}
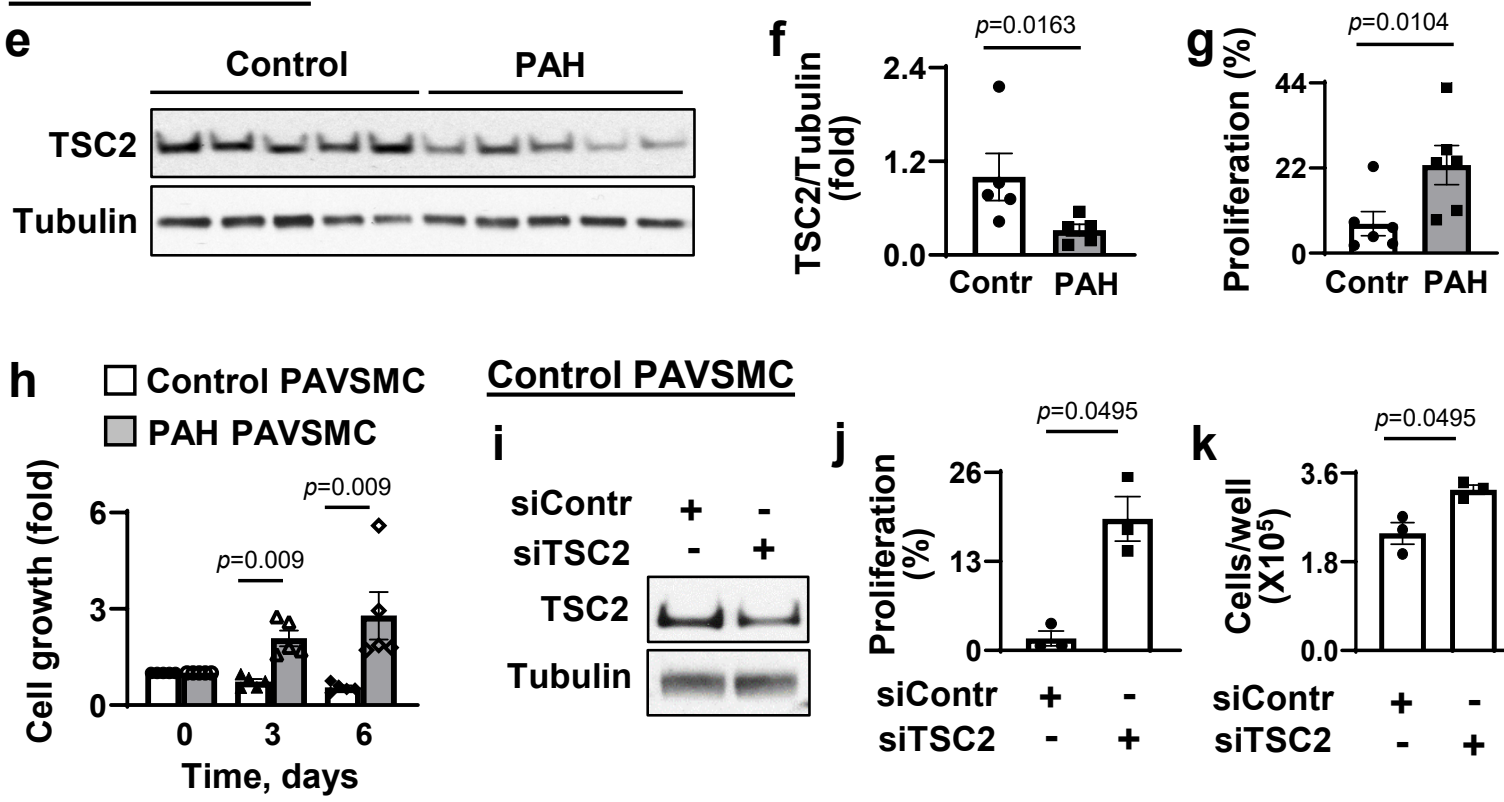

Control PAVSMC
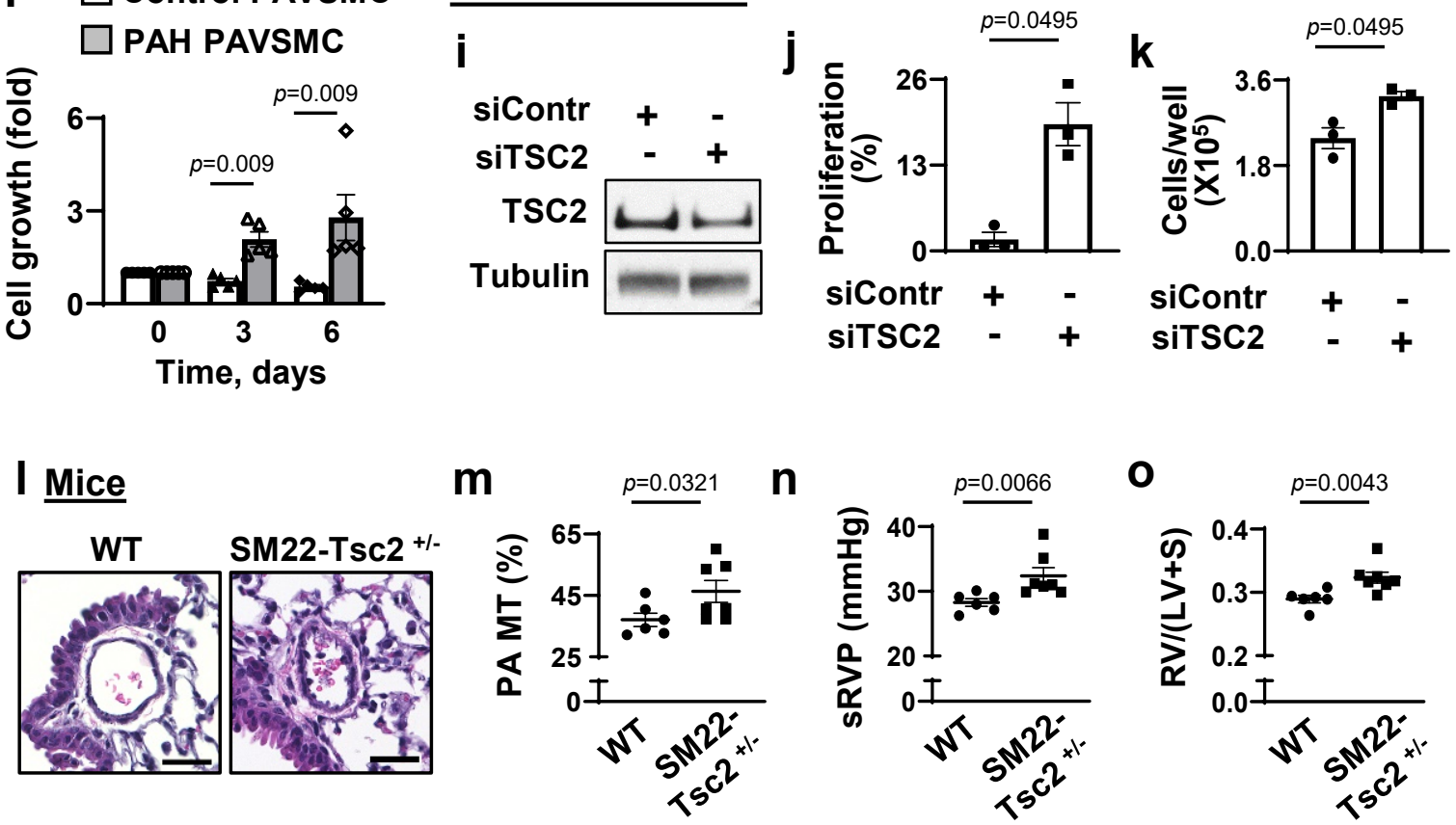
a, b. (a) Immunohistochemical analysis of human lung tissue sections to detect TSC2 (magenta), SMA (green) and DAPI (blue). Bar equals $100 \mu \mathrm{m}$. Images are representative from 3 subjects/group, $6 \mathrm{PA} /$ subject. (b) Optical density (OD) measurement of TSC2 fluorescent signal in SMA-positive regions of human small PAs. Data are means \pm SE from 3 subjects/group, $6 \mathrm{PA} /$ subject, 12 areas/PA, fold change to control. Statistical analysis by Mann Whitney $\mathrm{U}$ test (significance $p<0.05$ ), PAH vs. control.

c,d. Immunoblot analysis of small PAs. Data are means $\pm \mathrm{SE}$ from $\mathrm{n}=3$ subjects/group. Statistical analysis by Mann Whitney U test (significance $p<0.05$ ), PAH vs. control.

e,f. Immunoblot analysis of human non-diseased (control) (white bars) and PAH (grey bars) PAVSMC. Data are means \pm SE, fold change to control; $n=5$ subjects/group. Statistical analysis by Mann Whitney U test (significance $p<0.05$ ), PAH vs. control.

g. Proliferation (Ki67) of human control and PAH PAVSMC. Data represent \% of Ki67positive cells per total number of cells (detected by DAPI); data are means \pm SE from $n=6$ subjects/group; statistical analysis by Mann-Whitney U test (significance $\mathrm{p}<0.05$ ), PAH vs. control.

h. Equal quantity of cells was plated on each well of 6-well plate (day 0), cell counts were performed at days 3 and 6 . Data are fold change to day 0 . Data are means \pm SE from $n=5$ subjects/group; statistical analysis by Mann-Whitney $\mathrm{U}$ test (significance $p<0.05$ ), PAH vs. control.

i-k. Immunoblot (i), proliferation (DNA synthesis by BrdU incorporation) (j) and cell growth (cell counts) analyses (k) performed on the control human PAVSMC transfected with siRNA TSC2 (siTSC2) or control siRNA GLO (siContr) for 48 hours. Data are means \pm SE, from $n=3$ subjects/group; statistical analysis by Mann-Whitney U test (significance $p<0.05$ ), siTSC2 vs. siContr.

l-o. Morphological and hemodynamic analysis of 9 weeks-old male SM22-Tsc2 ${ }^{+/-}$and wild type (WT) mice. I: Images are representative from 6 mice/group, 12 PA/mouse. Bar equals 30 $\mu \mathrm{m}$. m-o: PA medial thickness (PA MT) (m), systolic RV pressure (sRVP) (n), and Fulton index (right ventricle $(\mathrm{RV}) /($ left ventricle $(\mathrm{LV})+$ septum) (o). Data are means $\pm \mathrm{SE} ; \mathrm{n}=6$ mice/WT; $\mathrm{n}=7$ mice/SM22-Tsc2 ${ }^{+/}$group; statistical analysis by Mann-Whitney U test (significance $p<0.05$ ), SM22-Tsc2 ${ }^{+/}$vs. WT. 
Figure 2. TSC2 deficiency is induced by increased substrate stiffness and is required for YAP/TAZ accumulation, activation of Akt and mTOR, and increased growth of PAVSMC

Control human PAVSMC

a soluble factors

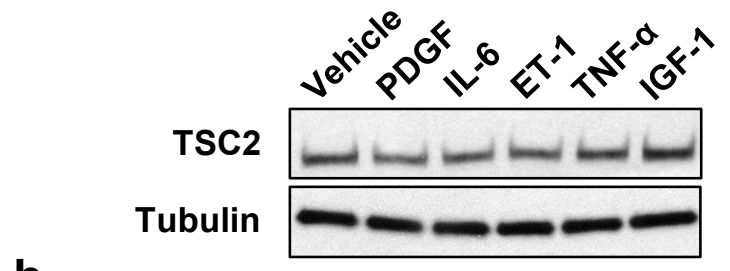

b

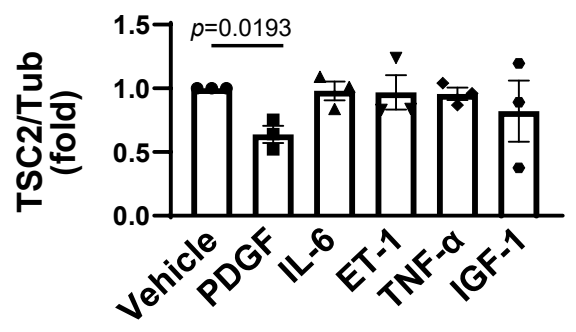

e matrix stiffness

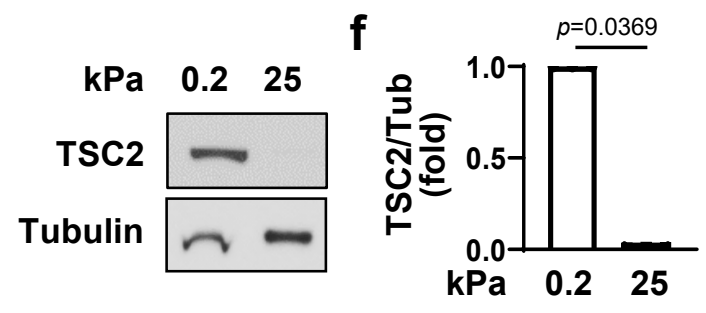

C matrix proteins
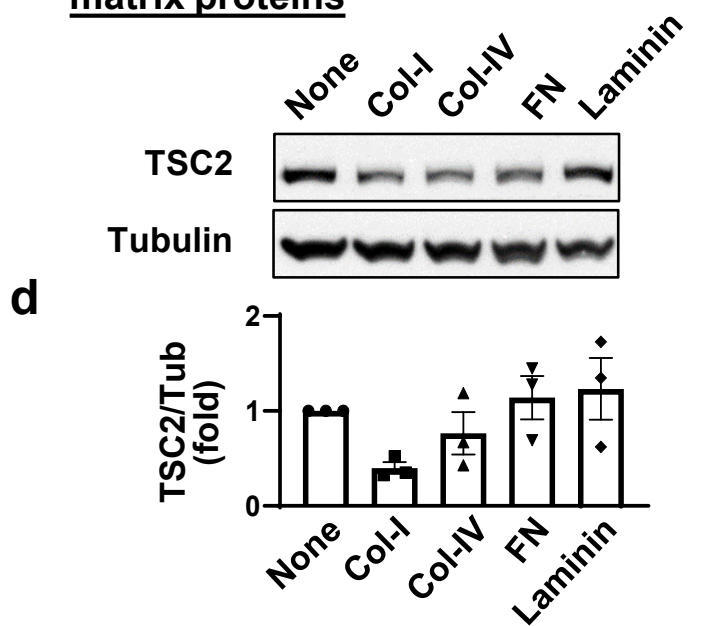

g

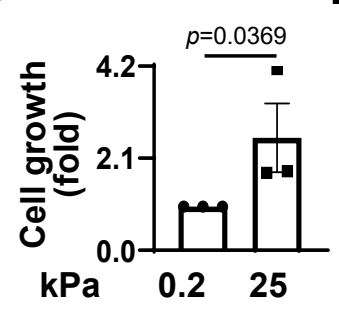

h $25 \mathrm{kPa}$ stiffness

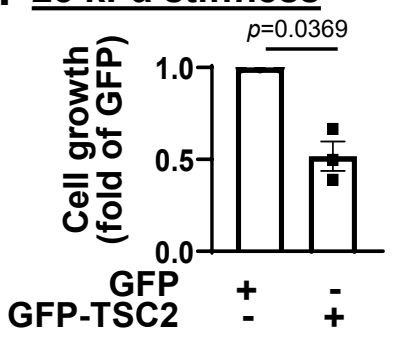

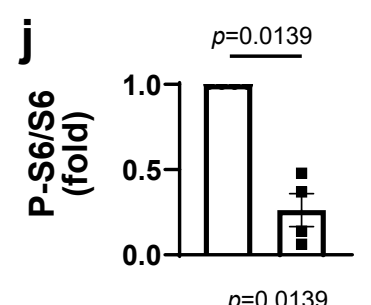

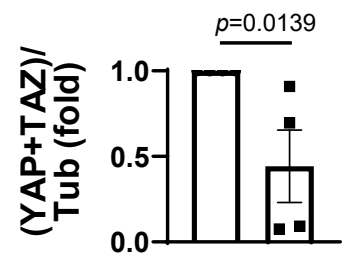

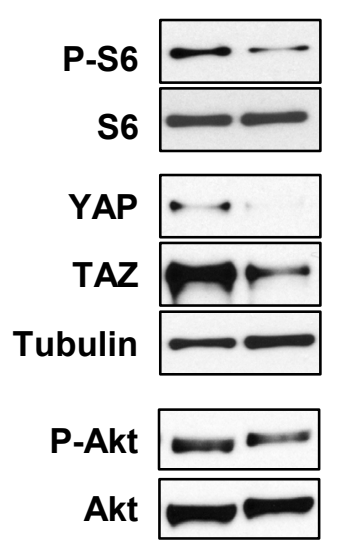

P-Akt

Akt
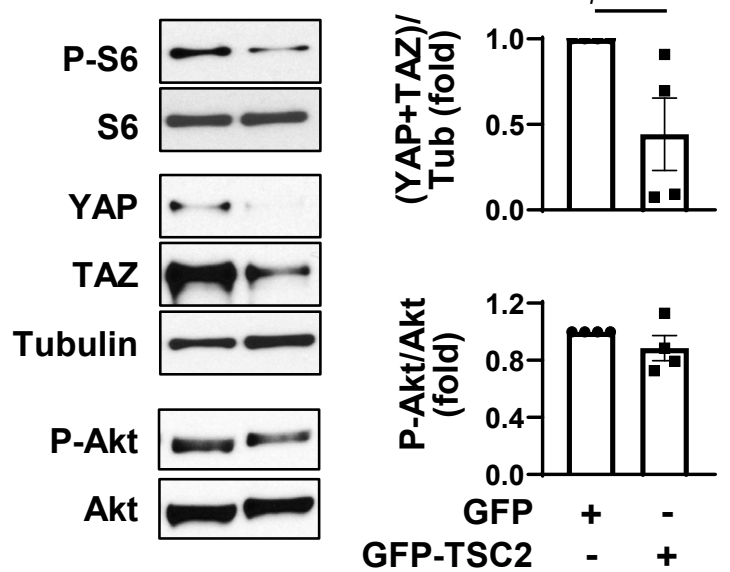

k
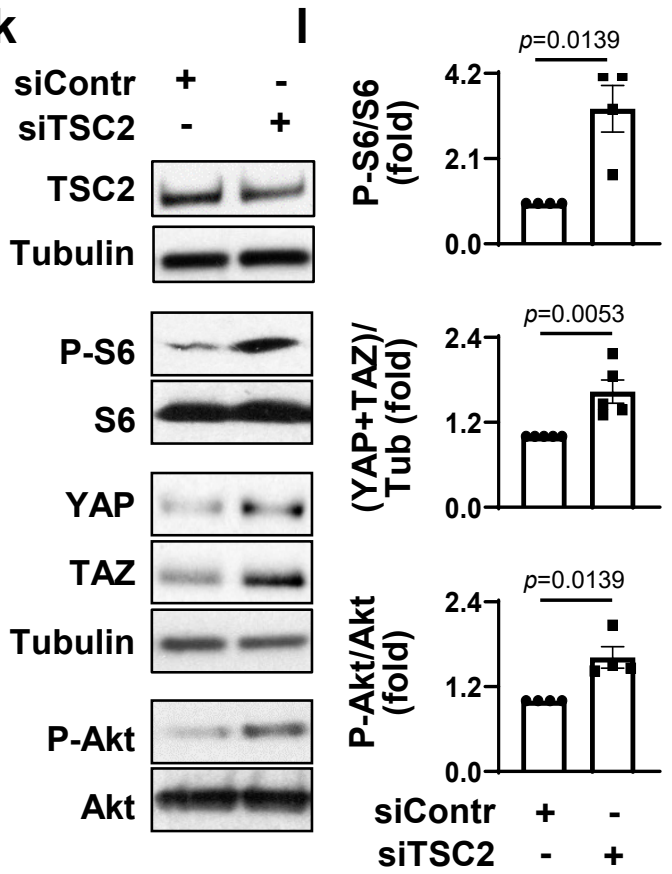
a-d. Immunoblot analysis of control human PAVSMC treated with indicated soluble factors $(\mathbf{a}, \mathbf{b})$ or maintained on the indicated matrices $(\mathbf{c}, \mathbf{d})$ for 48 hours. Data are means $\pm \mathrm{SE}$; fold change to vehicle treatment or none-coated matrix from $\mathrm{n}=3$ subjects/group; statistical analysis by Kruskal-Wallis test with Dunn's Pairwise Comparison (significance $p<0.025$ ).

e, f. Immunoblot analysis of control human PAVSMC maintained on the softwell hydrogels with normal $(0.2 \mathrm{kPa})$ or pathological $(25 \mathrm{kPa})$ stiffness for 48 hours. Data are means $\pm \mathrm{SE}$, fold change to $0.2 \mathrm{kPa}$ from $\mathrm{n}=3$ subjects/group; statistical analysis by Mann Whitney U test (significance $p<0.05$ ), $25 \mathrm{kPa}$ vs. $0.2 \mathrm{kPa}$.

g. Equal amounts of control human PAVSMC were plated at the hydrogels with $0.2 \mathrm{kPa}$ or 25 $\mathrm{kPa}$ stiffness, and cell growth assay (cell counts) was performed at day 4. Data are means $\pm \mathrm{SE}$, fold change to $0.2 \mathrm{kPa}$ from $\mathrm{n}=3$ subjects/group; statistical analysis by Mann Whitney $\mathrm{U}$ test (significance $p<0.05$ ), $25 \mathrm{kPa}$ vs. $0.2 \mathrm{kPa}$.

$\mathbf{h}, \mathbf{i}, \mathbf{j}$. Human control PAVSMC, plated on the softwell hydrogels with $25 \mathrm{kPa}$ stiffness were transfected with mammalian vectors expressing GFP or GFP-tagged human TSC2 for 36 hours. Cell growth assay (cell counts) and immunoblot analysis were performed. Data are means $\pm \mathrm{SE}$, fold change to GFP transfection from $\mathrm{n}=3$ (cell counts) and 4 (immunoblots) subjects/group; statistical analysis by Mann Whitney U test (significance $p<0.05$ ), GFP-TSC2 vs. GFP.

k, l. Human control PAVSMC were transfected with siRNA TSC2 ( GLO (siContr); 48 hours later, immunoblot analysis was performed. Data are means \pm SE, fold change to siContr from $\mathrm{n}=4$ or 5 subjects/group; statistical analysis by Mann Whitney U test (significance $p<0.05$ ), siTSC2 vs. siContr. 
Figure 3. TSC2 loss in PAVSMC modulates YAP/TAZ and mTOR, promotes growth of nondiseased pulmonary vascular cells via extracellular matrix remodeling (see also Supplemental Fig.S3, S4, and S5 for additional data)
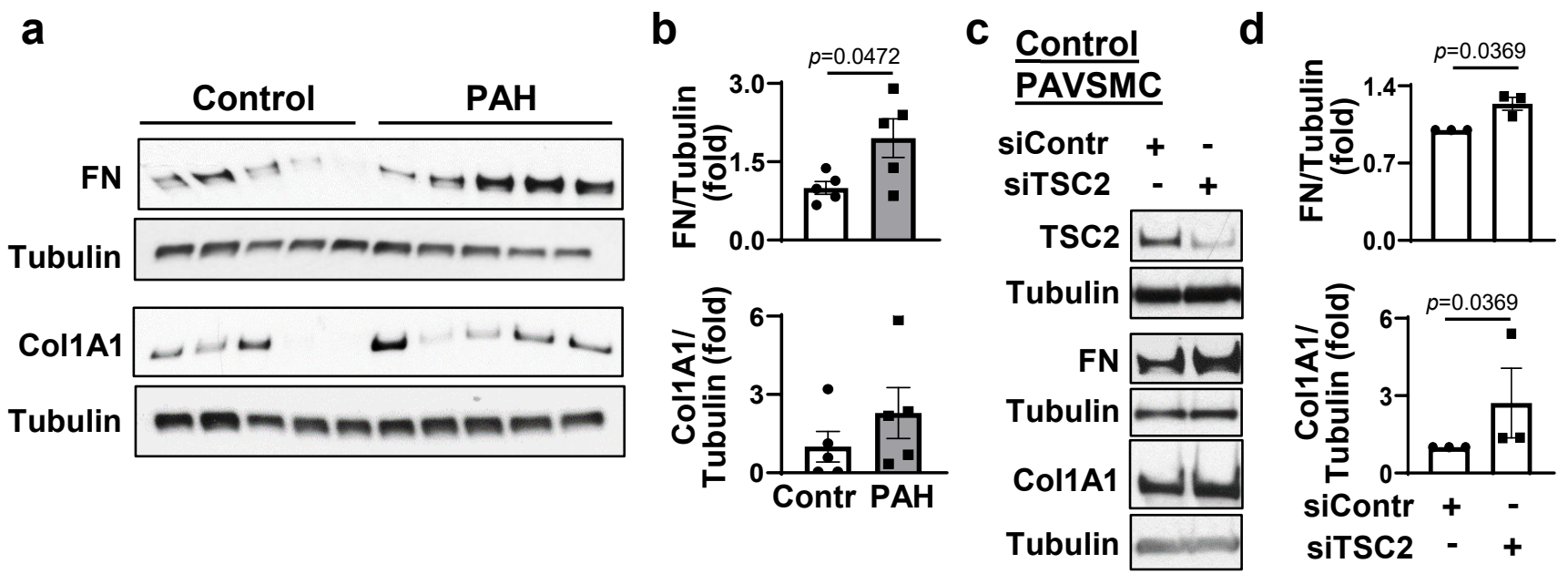

e

Control PAVSMC:

+ shContr

$+\operatorname{shTSC2}$

De-cellularize

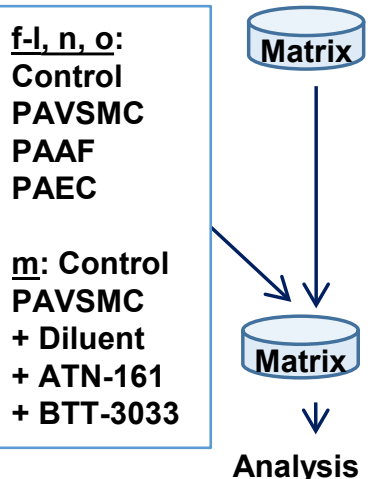

\section{PAVSMC on the PAVSMC-produced matrices}

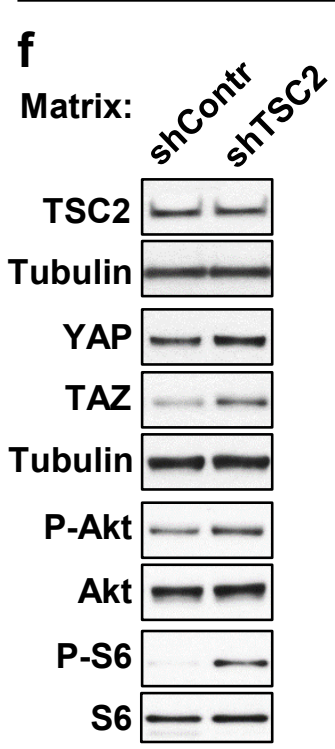

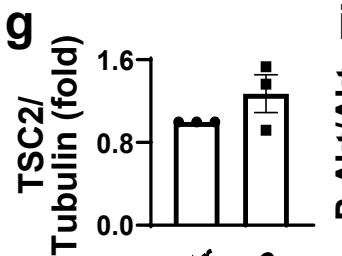

Matrix:<smiles>C1=[Ge]=C[Ge]1</smiles>

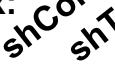

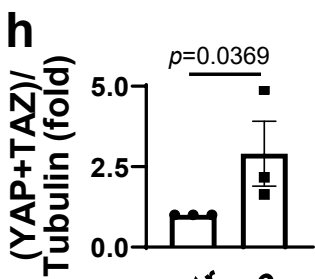

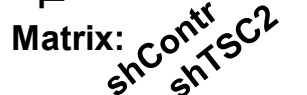

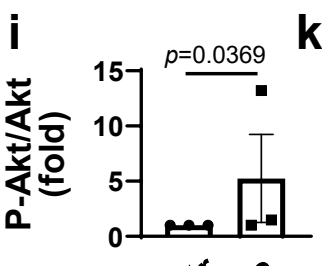

k

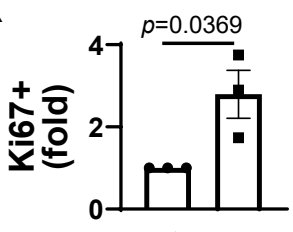

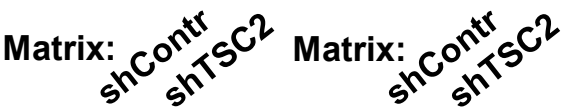
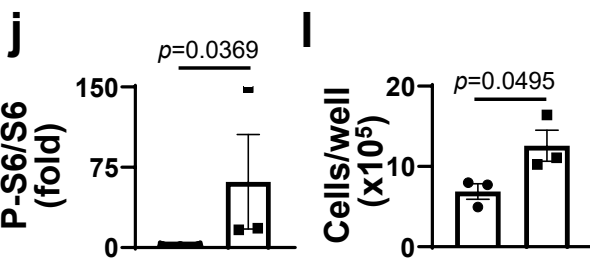

Matrix:

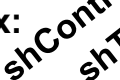

Matrix: ${ }^{2} \mathrm{Co}^{\mathrm{On}}{ }^{\mathrm{n}} \mathrm{se}$ m

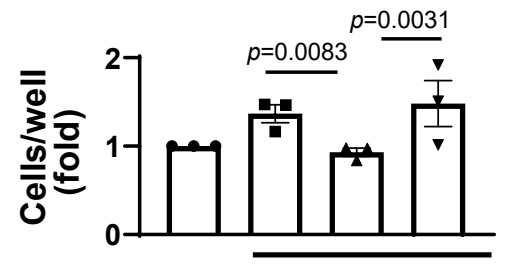

Matrices: shContr shTSC2

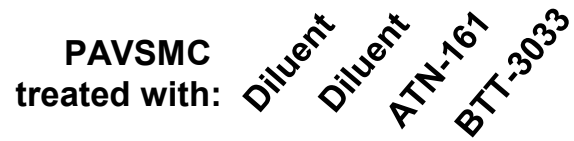

PAAF and PAEC on the PAVSMC-produced matrices

n

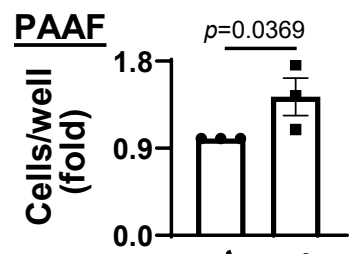

Matrix:
- PAEC

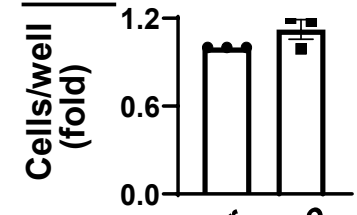

Matrix: 
a, b. Immunoblot analysis of control and PAH PAVSMC (5 subjects/group) to detect fibronectin (FN) and collagen 1A1 (Col1A1). Data are means \pm SE, fold change to control. $\mathrm{p}<0.05$ by Mann-Whitney $U$ test.

c, d. Immunoblot analysis of human control PAVSMC transfected with siRNA TSC2 (siTSC2) or control siRNA GLO (siContr) to detect FN and Col1A1. Data are means \pm SE from $\mathrm{n}=3$ subjects/group, fold change to siContr; statistical analysis by Mann Whitney U test (significance $p<0.05$ ).

e-o. Pre-confluent control PAVSMC were infected with shRNA control (shContr) or shRNA TSC2 (shTSC2) adenovirus and maintained for 6 days. Then cells were removed and equal amount of non-diseased (control) PAVSMC, untreated (f-I) or PAVSMC treated with diluent, $10 \mu \mathrm{M}$ ATN161 (integrin $\alpha 5 \beta 1$ inhibitor), or $10 \mu \mathrm{M}$ BTT3033 (integrin $\alpha 2 \beta 1$ inhibitor) (m), control PAAF (n), or control PAEC (o) were plated on the remaining matrices. Four days post-plating, immunoblot analysis (f-j), proliferation (Ki67) (k), and cell growth assays (cell counts) (l-q) were performed. Data are means \pm SE from $n=3$ subjects/group, statistical analysis by Mann Whitney $\mathrm{U}$ test (significance $p<0.05)(\mathbf{g}-\mathbf{l}, \mathbf{n}$, o) and by Kruskal-Wallis test with Dunn's Pairwise Comparison (significance $p<0.025$ ). (m). 
Figure 4. TSC2 expression reduces YAP/TAZ accumulation and fibronectin production, suppresses proliferation and induces apoptosis in human PAH PAVSMC (see also Supplemental Fig. S6 for additional data)

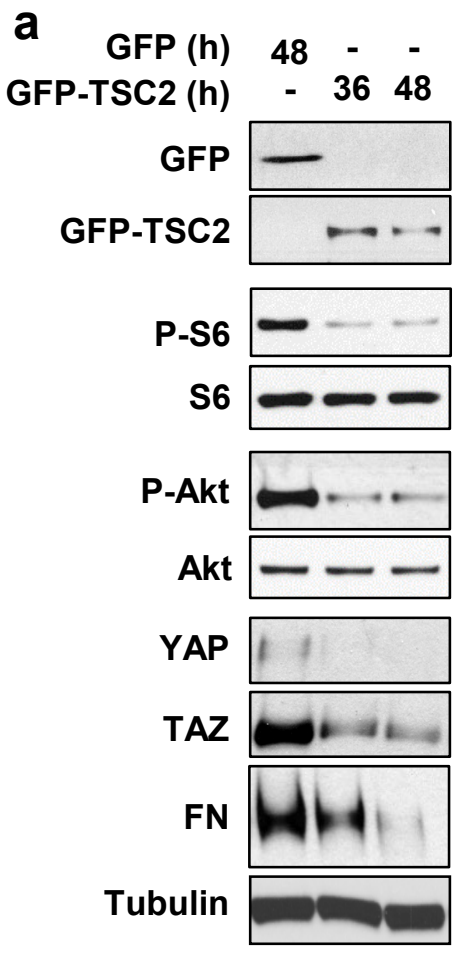

b


a, b. Human PAH PAVSMC were transfected with mammalian vectors expressing GFP or GFPTSC2 for indicated times followed by immunoblot analysis to detect indicated proteins. Data are means \pm SE from 3 subjects/group; statistical analysis by Kruskal-Wallis rank test with Dunn's Pairwise Comparison (significance $p<0.025$ ).

c-e. DNA synthesis (BrdU) (c), apoptosis (TUNEL) (d), and immunocytochemical analysis to detect cleaved caspase 3 (Cl. Casp3, red), GFP (green), and DAPI (blue). Data are means \pm SE from 3 subjects/group; statistical analysis by Mann-Whitney U test (significance $p<0.05$ ). Images are representative from cells from 3 different subjects; a minimum of 12 transfected cells/subject/condition. Bar equals $50 \mu \mathrm{m}$. White arrows indicate transfected cells. 
Figure 5. SRT2104 restores functional TSC2, inhibits proliferation and induces apoptosis in human PAH PAVSMC (see also Supplemental Fig. S7 for additional data)

\section{Human PAH PAVSMC}
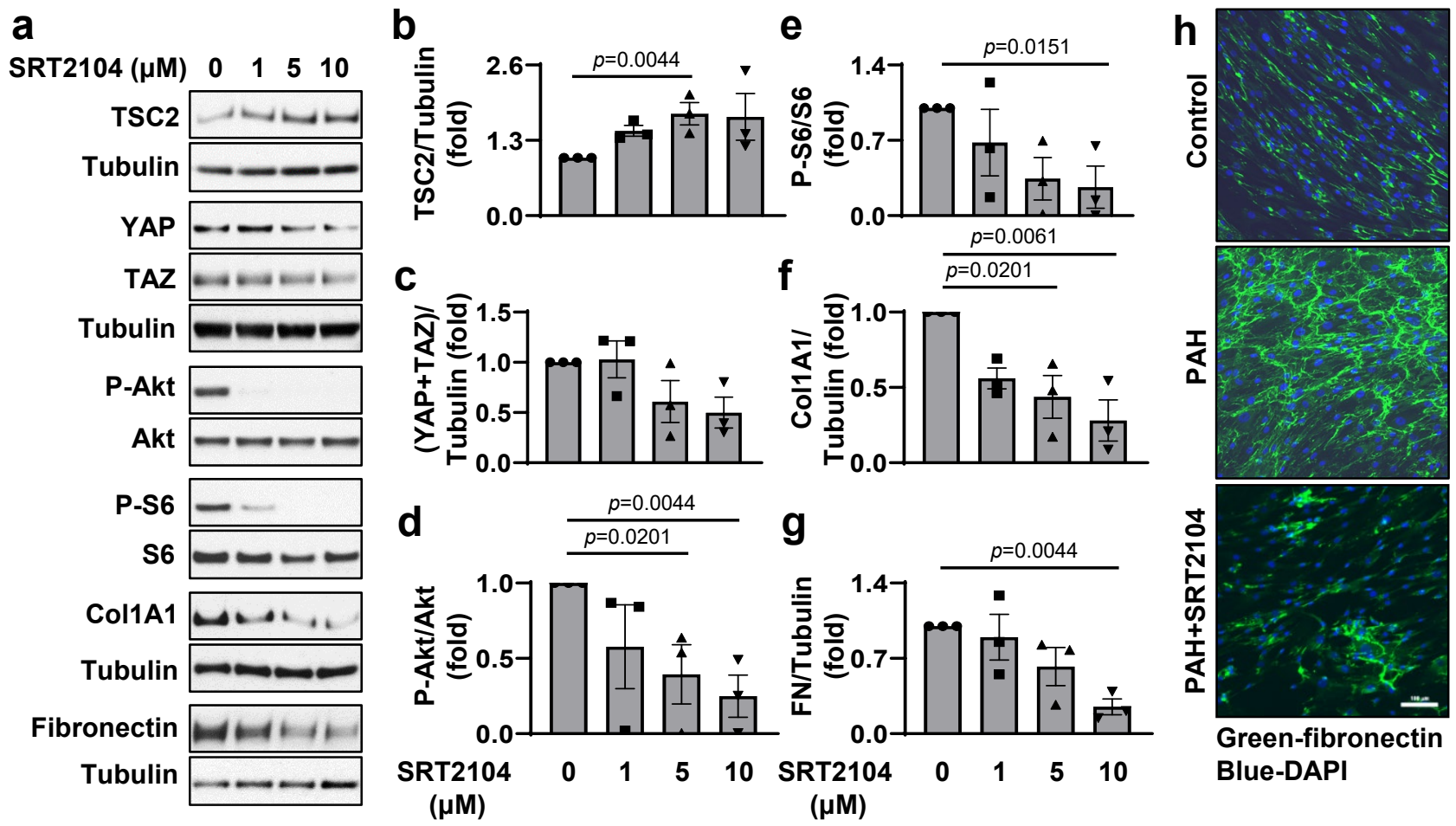

Green-fibronectin Blue-DAPI $\mathrm{SRT2104}$
$(\mu \mathrm{M})$$\quad 0 \quad 1 \quad 5 \quad 10 \begin{gathered}\mathrm{SRT210} \\ (\mu \mathrm{M})\end{gathered}$
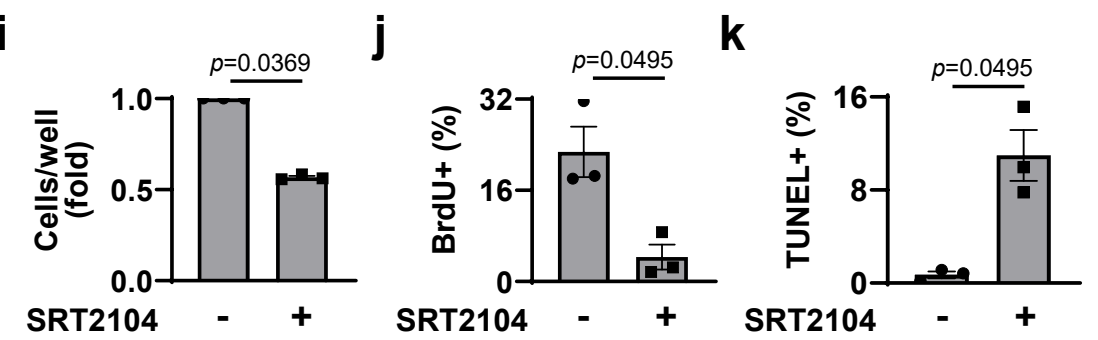

Human control PAVSMC

\section{Human PAH PAVSMC}
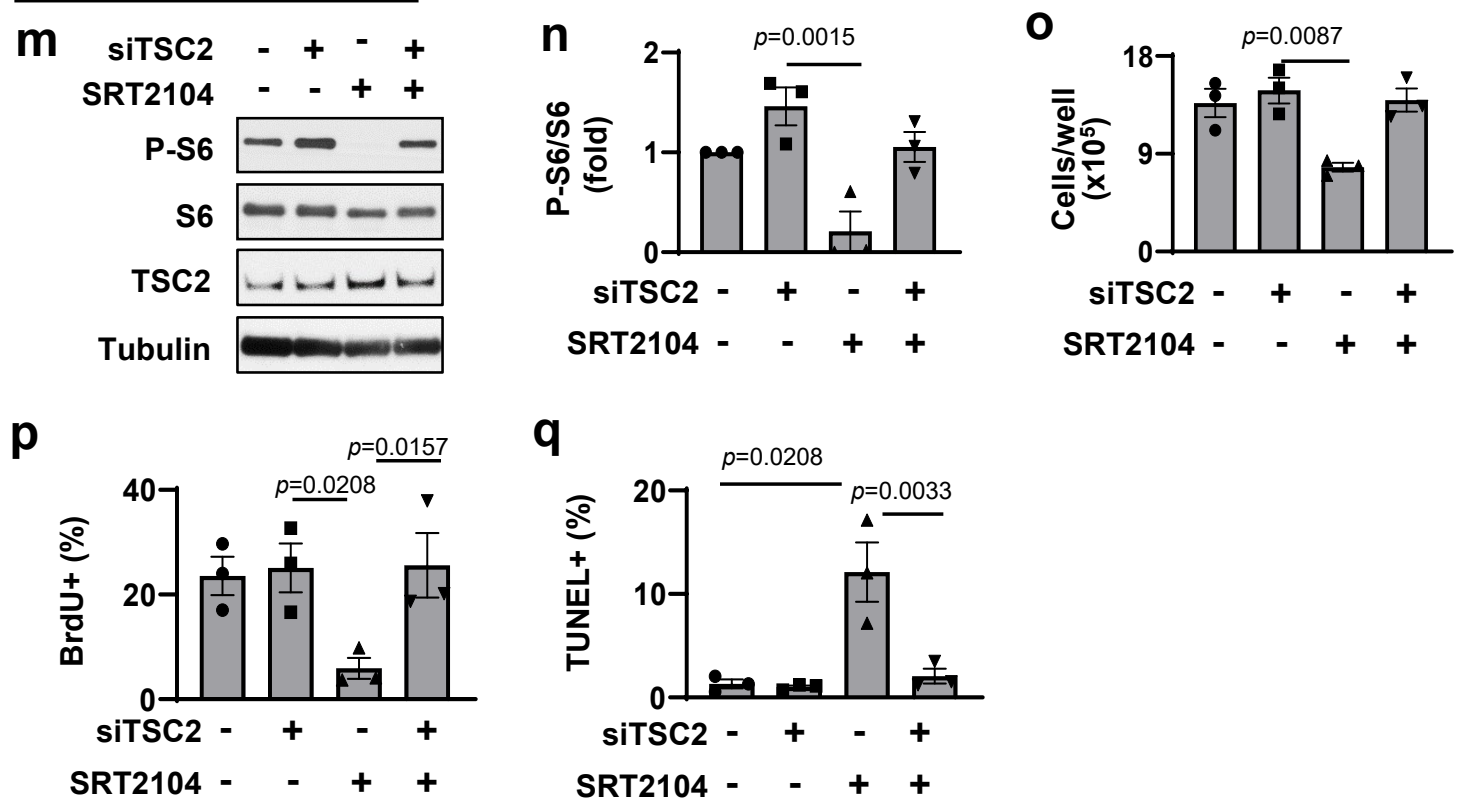
a-g. Immunoblot analysis of human PAH PAVSMC treated with diluent (0) or indicated concentrations of SRT2104 to detect indicated proteins. Data are means \pm SE from 3 experiments, each performed on the cells from different subject; statistical analysis by KruskalWallis rank test with Dunn's Pairwise Comparison (significance $p<0.025$ ), vs. diluent $(0)$.

h. Immunocytochemical analysis to detect fibronectin of human non-diseased (control) and PAH PAVSMC treated with diluent or $10 \mu \mathrm{M}$ SRT2104 for $48 \mathrm{hr}$. Bar equals $100 \mu \mathrm{m}$.

i-k. Human PAH PAVSMC were treated with diluent (-) or $10 \mu \mathrm{M}$ SRT2104 (+) for $48 \mathrm{hr}$; cell counts (i), proliferation (BrdU incorporation) (j) and apoptosis (TUNEL) (k) analyses were performed. Data are means \pm SE from 3 experiments, each performed on the cells from different subject; statistical analysis by Mann-Whitney U test (significance $p<0.05)$ vs. diluent $(0)$.

1. Equal amount of human control PAVSMC were seeded on hydrogels with $25 \mathrm{kPa}$ stiffness and treated with diluent (-) or $10 \mu \mathrm{M}$ SRT2104 (+) for 48hr; then cell growth analysis (cell counts) was performed. Data are means \pm SE from 3 experiments, each performed on the cells from different subject; statistical analysis by Mann Whitney $U$ test (significance $p<0.05$ ) vs. diluent (0).

m-q. Immunoblot, cell growth, proliferation (BrdU incorporation) and apoptosis (TUNEL) analyses of PAH PAVSMC transfected with siContr or siTSC2 and treated with $10 \mu \mathrm{M}$ SRT2 104 or diluent for $48 \mathrm{hr}$. Data are means $\pm \mathrm{SE}$ from 3 experiments, each performed on the cells from different subject; statistical analysis by Kruskal-Wallis rank test with Dunn's Pairwise Comparison (significance $p<0.025)$ vs. siContr (Scr)+diluent (-/-). 
Figure 6. SRT2104 restores Tsc2 in small PAs, attenuates PH and reduces RV hypertrophy in mice (see also Supplemental Fig. S8 for additional data)

\section{a C57/BL6 Mice}

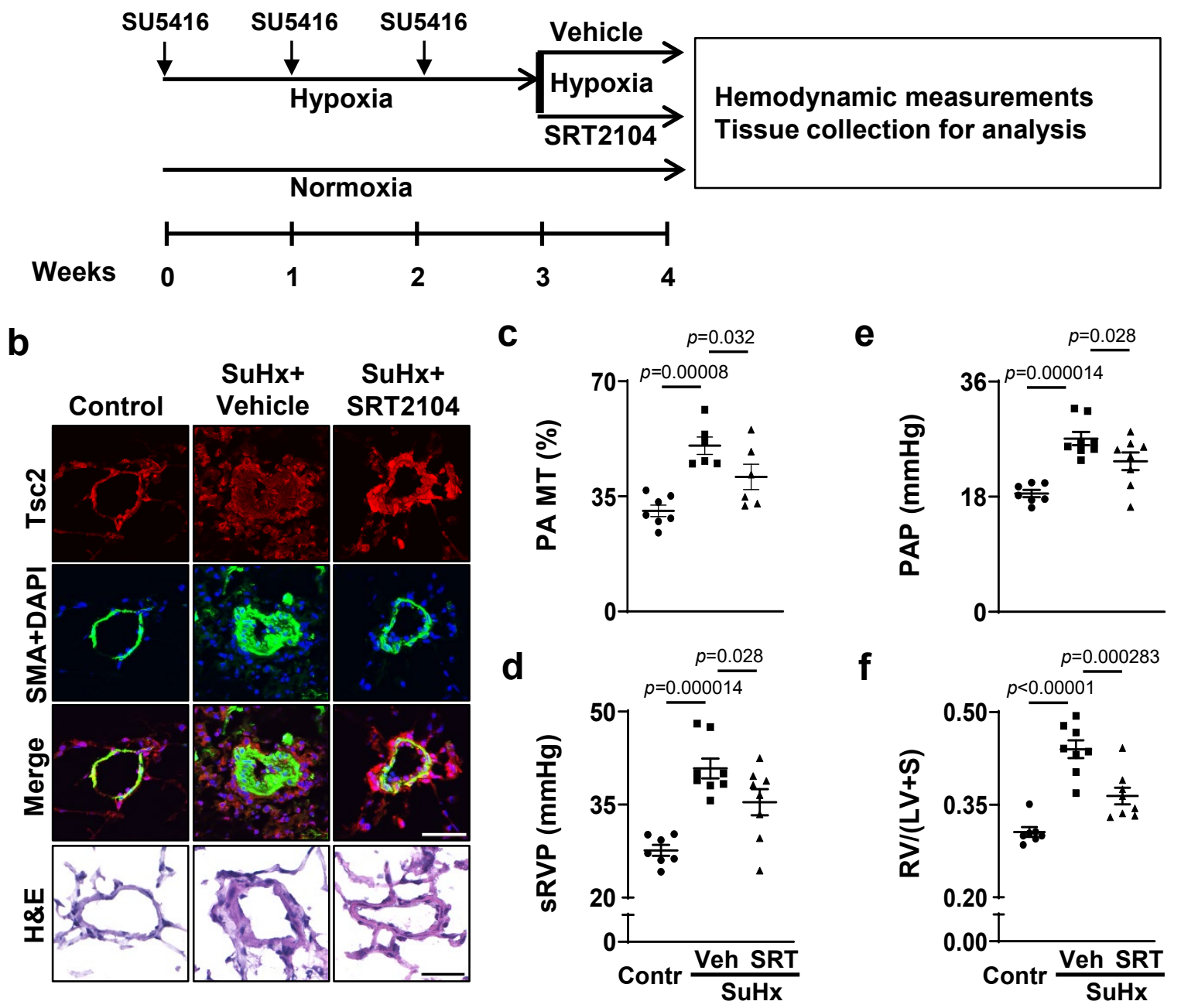

a. Schematic representation of the experiment. 6-8 weeks old male and female mice maintained under hypoxia for three weeks and received SU5416 injection at the beginning of every week. Starting week 4, mice, still kept under hypoxia, were randomly assigned to two groups and then treated with SRT2104 (SRT) or vehicle (Veh) for 1 week, 5 days/week. Controls were same-age and -sex mice kept under normoxia. Upon experiment termination, hemodynamic measurements were performed, lung and heart tissues were collected for analysis. Control mice were same-age and -sex mice maintained under normoxia.

b. immunohistochemical (IHC) analysis to detect Tsc2 (red), SMA (green), and DAPI (blue), bar equals $80 \mu \mathrm{m}$; images are representative from 3 mice/group, 12 PAs/mice. H\&E staining bar equals $30 \mu \mathrm{m}$, images are representative from $7 \mathrm{mice} / \mathrm{control}, 6 \mathrm{mice} / \mathrm{SuHx}+$ Vehicle and $\mathrm{SuHx}+\mathrm{SRT} 2104$ groups, 12 PAs/mice.

c-f. (c) PA medial thickness (PA MT) is calculated by 12-24 PAs/mouse; data are means $\pm \mathrm{SE}$ from $\mathrm{n}=7$ mice for control $(3 \hat{\partial}, 4$ + $), \mathrm{n}=6$ mice for $\mathrm{PH}(3 \hat{\jmath}, 3$ + $), \mathrm{n}=6$ mice for $\mathrm{PH}+\mathrm{SRT} 2104$ $(3 \hat{O}, 3$ q $)$ groups; statistical analysis by one-way ANOVA (significance $p<0.05)$. Systolic right ventricular pressure (sRVP) (c), pulmonary arterial pressure (PAP) (d), and Fulton index $(\mathrm{RV} /(\mathrm{LV}+$ septum) weight ratio) (e); data are means $\pm \mathrm{SE}$ from $\mathrm{n}=7$ mice for control $(3 \hat{\jmath}$, 4 ㅇ), $\mathrm{n}=8$ mice for $\mathrm{PH}(4 \hat{\bigcirc}, 4+$ ㅇ), $\mathrm{n}=8$ mice for $\mathrm{PH}+\mathrm{SRT} 2104(4 \hat{\bigcirc}, 4+$ ) groups; statistical analysis by one-way ANOVA (significance $p<0.05$ ). 
Figure 7. SRT2104 restores Tsc2 in small PAs, attenuates $P H$ and reduces $R V$ hypertrophy in rats (see also Supplemental Fig. S8 for additional data)

\section{a Sprague-Dawley Rats}
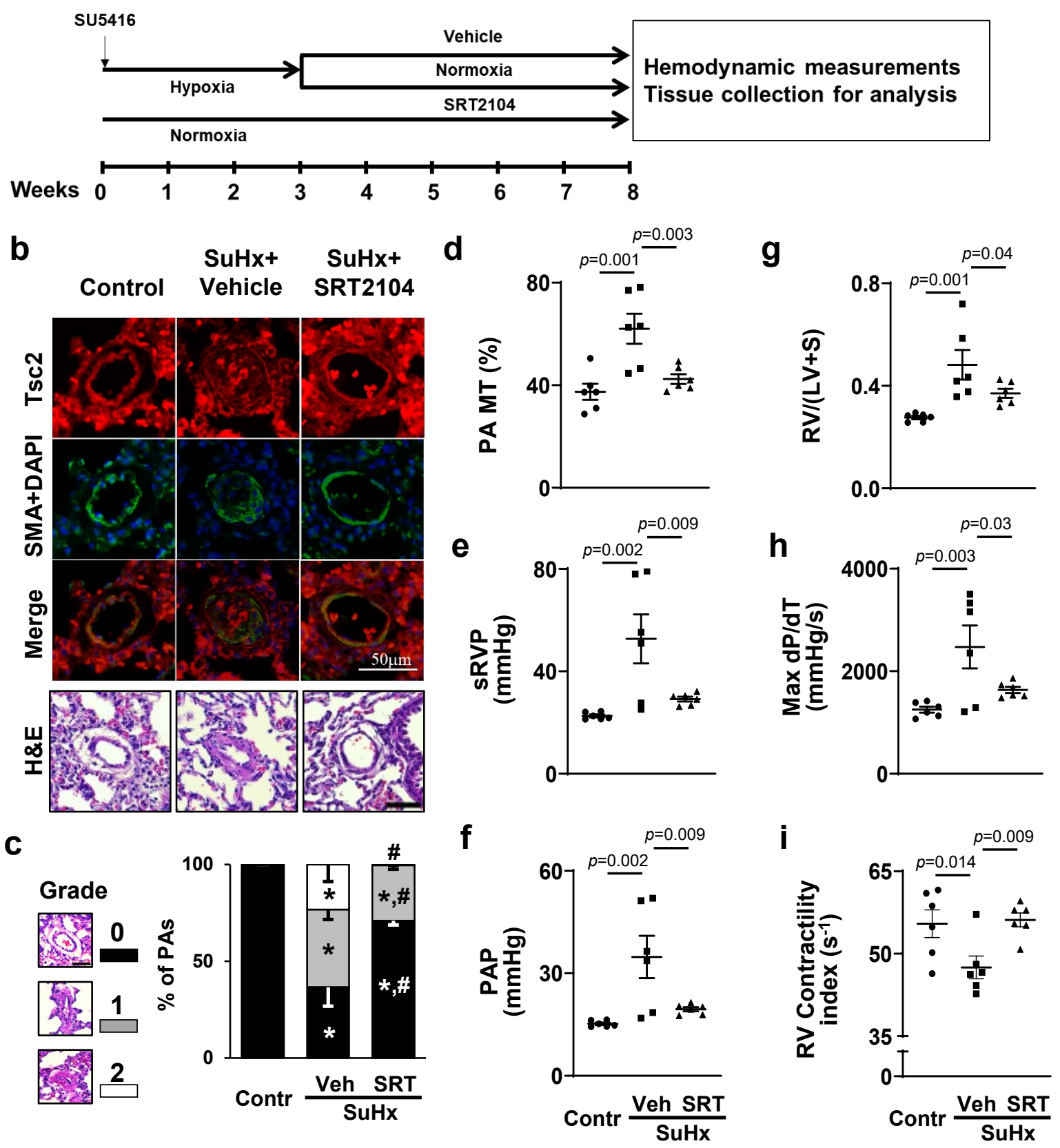

a. Schematic representation of the experiment. Male 6-8 weeks old rats received one SU5416 injection and maintained under hypoxia for three weeks. Starting week 4 , rats, transferred to the normoxia conditions, were randomly assigned to two groups and then treated with SRT2104 (SRT) or vehicle (Veh) for 5 weeks, 5 days/week (days 21-56 of experiment) followed by hemodynamic and morphological analyses. Controls were same-age male rats kept under normoxia for 8 weeks. b. IHC to detect Tsc2 (red), SMA (green) and DAPI (blue) and H\&E analyses; bar equals $50 \mu \mathrm{m}$, images are representative from 6 rats/group, 12 PAs/rat. c-i: percentage of fully (grade 2), partially (grade 1) and not occluded PAs (grade 0), bar equals $50 \mu \mathrm{m}$ (c), PA MT (d), sRVP (e), PAP (f), Fulton index (g), RV contractility $(\operatorname{Max}(\mathrm{dP} / \mathrm{dt}))(\mathbf{h})$, and RV Contractility index (i) measured at day 56 of experiment. Data are means \pm SE from 6 rats/group. ${ }^{*} p<0.05$ vs control, ${ }^{\#} p<0.05$ vs $\mathrm{PH}$ by one-way ANOVA (significance $p<0.05$ ). 
Figure 8. Schematic representation of the mechanism by which TSC2 loss in PAVSMC promotes pulmonary vascular remodeling and pulmonary hypertension.

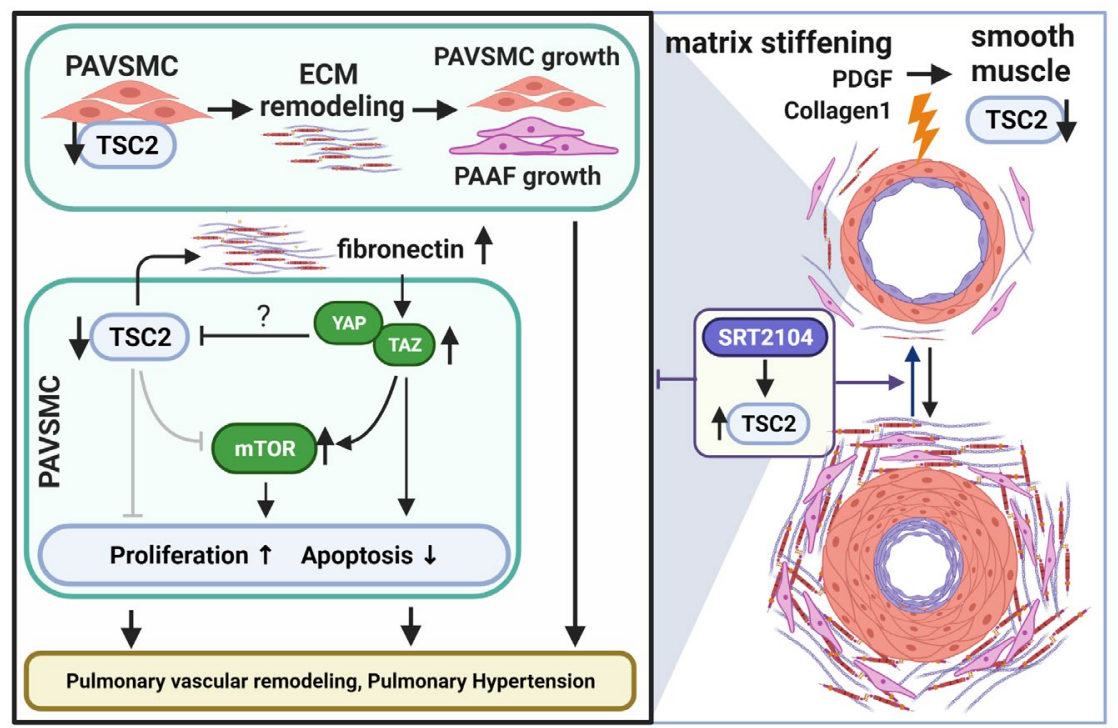

